\section{Análise da relação entre a paisagem e a hidrogeoquímica da bacia hidrográfica do rio Moju, Amazônia Oriental-Brasil}

\section{Analysis of the relationship between landscape and hydrogeochemistry of the Moju river basin, Eastern Amazon-Brazil}

\author{
Aline Maria Meiguins de Lima \\ Universidad Federal de Pará \\ Pará, Brasil \\ ameiguins@ufpa.br \\ (iD https://orcid.org/0000-0002-0594-0187
}

\section{José Augusto Martins Corrêa}

Universidad Federal de Pará

Pará, Brasil

jamc@ufpa.br

(iD) https://orcid.org/0000-0002-6179-6159

\section{Letícia Magalhães da Silva}

Universidad Federal de Pará

Pará, Brasil

leticia.magalhaes@live.com

iD https://orcid.org/0000-0003-0504-956X

\section{Susane Cristini Gomes Ferreira}

Universidad Federal de Pará

Pará, Brasil

susane_cristini@hotmail.com

iD https://orcid.org/0000-0002-8869-4144

Información del artículo:

Recibido: 11 noviembre 2019

Revisado: 31 mayo 2020

Aceptado: 9 junio 2020

$\begin{array}{ll}\text { ISSN } & 2340-8472 \\ \text { ISSNe } & 2340-7743 \\ \text { DOI } & 10.17561 / \text { AT.17.5041 }\end{array}$

\section{RESUMO}

A bacia do rio Moju (Amazônia Oriental-Brasil) foi avaliada considerando os elementos formadores da paisagem (biofísicos e de uso da terra) e seu reflexo na qualidade das águas. o período de análise correspondeu a um ciclo hidrológico completo, com a avaliação espacial das formas de uso e cobertura da terra e caracterização dos componentes hidrogeomofológicos estruturantes. Os resultados indicaram a associação do efeito natural responsável pelo padrão de águas cloretadas-sódicas com as possíveis intervenções geradas pela expansão da cultura do dendê no Médio Moju e com o processo de ocupação territorial no Alto Moju. O Baixo Moju se destaca pela proximidade com a Região Metropolitana de Belém, tornando a bacia de maneira integral vulnerável quanto à pressão antrópica sobre as águas superficiais.

PALAVRAS-CHAVE: Recursos hídricos, Qualidade das águas,

Hidrogeomofologia, Bacia do rio Moju, Brasil.

\section{ABSTRACT}

The Moju river basin was evaluated considering the landscape forming elements (bio-physical and land use) and their reflection on water quality. The analysis period corresponded to a complete hydrological cycle, with the spatial evaluation of land use and land cover and its hydrogeomophological components. The results showed the association of the natural effect responsible for the sodiumchloride water pattern and the possible interventions generated by the expansion of palm oil production in the Middle Moju and the territorial occupation process in High Moju. Low Moju stands out for its proximity to the Belém Metropolitan Region, making the basin fully vulnerable to anthropogenic pressure on surface waters.

KEYWORDS: Water resources, water quality, hydrogeomophology, Moju river basin, Brazil. 


\section{Análisis de la relación entre paisaje y la hidrogeoquímica de la cuenca del río Moju, Amazonia Oriental, Brasil}

\section{RESUMEN}

La cuenca del río Moju (Amazonia Oriental-Brasil) fue evaluada considerando los elementos que forman el paisaje (bio-físico y uso de la tierra) y su reflexión sobre la calidad del agua. El análisis correspondió a un ciclo hidrológico, con evaluación espacial del uso y cobertura del suelo y caracterización de componentes hidrogeomofológicos estructurantes. Según los resultados, la asociación del efecto natural responsable del patrón de agua clorada y sódica con las posibles intervenciones generadas por la expansión de la producción de aceite de palma en el medio de Moju y del proceso de ocupación territorial en Alto Moju. Se destaca el Bajo Moju por su proximidad a la Región Metropolitana de Belém, lo que hace que la cuenca sea completamente vulnerable a la presión antropogénica en las aguas superficiales.

PALABRAS CLAVE: Recursos hídricos, Calidad del agua,

Hidrogeomofología, Cuenca del río Moju, Brasil.

Analyse de la relation entre le paysage et I'hydrogéochimie dans le bassin du fleuve Moju, Amazonie orientale, Brésil

\section{RÉSUMÉ}

le bassin de la rivière Moju (Amazonie orientale - Brésil) a été évalué en tenant compte des éléments qui forment le paysage (biophysique et utilisation des terres) et de sa réflexion sur la qualité de l'eau. L'analyse correspondait à un cycle hydrologique, avec une évaluation spatiale de l'utilisation et de la couverture des terres et la caractérisation des éléments structurants de l'hydrogéomorphologie. Selon les résultats, l'association de l'effet naturel responsable du schéma des eaux chlorées et sodiques avec les interventions possibles générées par l'expansion de la production d'huile de palme dans l'environnement de Moju et le processus d'occupation des terres dans l'Alto Moju. Le Bas Moju se distingue par sa proximité avec la région métropolitaine de Belém, ce qui rend le bassin complètement vulnérable à la pression anthropique sur les eaux de surface.

MOTS-CLÉS: Ressources en eau, Qualité de l'eau, Hydrogéomorphologie, Bassin du fleuve Moju, Brésil.

\section{Analisi del rapporto tra paesaggio e idrogeochimica nel bacino del fiume Moju, Amazzonia orientale, Brasile}

\section{SOMMARIO}

il bacino del fiume Moju (Amazzonia Orientale-Brasile) è stato valutato considerando gli elementi che formano il paesaggio (uso biofisico e del suolo) e la sua riflessione sulla qualità dell'acqua. L'analisi corrispondeva ad un ciclo idrologico, con valutazione spaziale dell'uso del suolo e della copertura e caratterizzazione dei componenti di strutturazione idrogeomofologica. Secondo i risultati, l'associazione dell'effetto naturale responsabile del modello di acqua clorurata e sodica con i possibili interventi generati dall'espansione della produzione di olio di palma nell'ambiente Moju e dal processo di occupazione del suolo nell'Alto Moju. Il Basso Moju si distingue per la sua vicinanza alla regione metropolitana di Belém, che rende il bacino completamente vulnerabile alla pressione antropica sulle acque superficiali.

PAROLE CHIAVE: Risorse idriche, Qualità dell'acqua, Idrogeomofologia, Bacino del fiume Moju, Brasile. 


\section{Introdução}

Mudanças ocorridas no uso e cobertura da terra através dos anos têm gerado impactos nos sistemas ecológicos e na qualidade das águas. A ação antropogênica se reflete na inter-relação dos componentes bióticos e abióticos dos ecossistemas existentes em uma bacia hidrográfica, podendo gerar uma heterogeneidade na paisagem com velocidade acima daquela em que naturalmente ocorreria, tornando necessária a avaliação das interações entre os diferentes atores sociais e econômicos que representam a bacia, sempre considerando as implicações ambientais ${ }^{1}$.

Os corpos hídricos que formam as bacias hidrográficas são escoadouros naturais das áreas de drenagem, justificando a presença de componentes de origem natural e antrópica ${ }^{2}$. A relação entre o levantamento dos usos da terra e a composição geoquímica das águas dos rios é de extrema importância para a compreensão das mudanças ocorridas em decorrência das diferentes formas do uso em questão, que influenciam na qualidade das águas ${ }^{3}$.

Estas mudanças desencadeiam processos como erosão, transporte de sedimentos e de elementos químicos bio-ativos (carbono, nitrogênio e fósforo) ${ }^{4}$. Portanto, as atividades antrópicas alteram significativamente a composição das águas - física, química e biologicamente- podendo ser prejudicial ao uso presente e futuro desse recurso natural.

Para ilustrar, há estudos que verificam a influência da vegetação natural remanescente e de atividades agrícolas na qualidade de quatro nascentes e, a partir daí, percebeu-se que as características do solo, seus diferentes usos e os períodos de amostragem tiveram reflexos nos resultados obtidos ${ }^{5}$, bem como a participação da estrutura química de rochas e solos na composição das águas de duas bacias hidrográficas de características rural e urbana ${ }^{6}$.

Na região Amazônica foram avaliadas ${ }^{7}$ as águas do rio Madeira, e seus principais tributários entre a cidade de Humaitá e sua foz no rio Amazonas, tendo sido verificado que a interação vegetação-solo-rocha é a causa da heterogeneidade química dessas águas. Em uma análise da dinâmica do uso da terra e da configuração da paisagem em três microbacias do nordeste do estado do Pará (Brasil), em antigas áreas de colonização de

\footnotetext{
1. Sanson e Hernández, 2018

2. Toledo e Nicolella, 2002

3. Chapman et al, 2016

4. Conley et al, 2009; Wang et al, 2014

5. Donadio et al, 2005

6. Moura et al, 2010

7. Horbe et al, 2013
}

base econômica familiar, os autores concluíram que as pastagens representam o padrão dominante de uso da terra, com impacto direto nas águas superficiais e subterrâneas ${ }^{8}$.

As modificações sofridas pela floresta amazônica para a implantação de atividades agropecuárias têm alterado a ciclagem de nutrientes e de carbono na Amazônia e, consequentemente, a qualidade da água, pois influenciam nos processos hidrológicos e biogeoquímicos atuantes ${ }^{9}$.

A bacia do rio Moju (Pará-Brasil) torna-se um exemplo de aplicação, pois está localizada em uma região que marca a faixa de transição entre a borda de floresta Amazônica e o estuário-foz do rio Amazonas, cuja dinâmica de uso da terra se aproxima mais daquelas observadas nas bacias que drenam o nordeste paraense e o rio Tocantins.

Em termos político-administrativos compõe as Mesorregiões do Nordeste e Sudeste Paraense, com uma delimitação mais específica definindo-a como pertencente as Microrregiões de Cametá, Tomé-Açu e Tucuruí. Esta é considerada como o principal polo de expansão da cultura do dendezeiro (Elaeis guineensis) devido às favoráveis condições edafoclimáticas, disponibilidade de área, logística e também por contar com uma cadeia produtiva com bom avanço no processo de estruturação ${ }^{10}$.

O plantio de dendê ganhou destaque devido à palmeira estar entre as melhores para a produção do biocombustível por sua composição, alta produtividade, baixo custo, produção distribuída ao longo de todo o ano, oferta regular e crescente, além de destinar-se a áreas distintas de produção, não competindo com outros cultivos alimentares. Ademais, os óleos de palma e de palmiste extraídos do dendezeiro também estão presentes na indústria alimentícia, de higiene e de limpeza e nas químicas ${ }^{11}$.

A cultura do dendê vem sendo alvo de críticas sob o argumento de provocar efeitos prejudiciais à biota $\mathrm{e}$ uma intensa fragmentação da paisagem ${ }^{12}$. A bacia hidrográfica do rio Moju, que tem destaque na produção de dendê no estado, serve como um instrumento aferidor das possíveis implicações produzidas nos recursos hídricos locais.

A expansão das atividades agropecuárias para áreas ripárias nas bacias amazônicas tem resultado

\footnotetext{
8. Watrin et al, 2009

9. Davidson et al, 2004

10. Santos et al, 2014

11. Bentes e Homma, 2016

12. Nahum e Santos, 2013; Nahum e Santos, 2016
} 
em redução da qualidade da água, haja vista que a presença de matas ciliares influencia no processo de controle da erosão, na dinâmica de nutrientes e na manutenção quantitativa de água para seu uso múltiplo ${ }^{13}$.

Os estudos hidrogeoquímicos merecem destaque nesta abordagem, pois altos níveis de contaminação por metais pesados, como cromo, cobre, zinco e chumbo, representam risco extremo para a população que faz uso destas águas e são capazes de causar a deterioração do equilíbrio físico e químico, com interferência direta na cadeia alimentar, levando a alterações fisiológicas e morfológicas dos organismos aquáticos ${ }^{14}$.

Tais fatores também estão relacionados ao comportamento hidrológico das bacias hidrográficas, considerando-se variações temporais e espaciais vinculadas, como por exemplo, a dependência sazonal do regime hídrico, a distribuição da precipitação pluviométrica, os padrões de cobertura da terra, o efeito topográfico, a variabilidade do comportamento geológico e, se houver, a influência das águas subterrâneas ${ }^{15}$.

Logo, a heterogeneidade do padrão da qualidade das águas amazônicas advém da associação entre suas características naturais (envolvendo aspectos geológicos e de cobertura de solos) e hidrodinâmicas (águas superficiais, subterrâneas e contribuição direta das chuvas), influenciadas pela variabilidade das formas de uso da terra ${ }^{16}$.

A análise da relação entre a hidrogeoquímica e as formas de uso da terra em bacias hidrográficas fluviais constitui objeto do presente estudo, tendo como unidade de referência, a bacia hidrográfica do rio Moju, que representa um padrão de transição, com a mudança da cobertura vegetal original para o sistema de produção extrativista e agropecuário, além de sofrer influência direta do regime vinculado ao estuário-foz do rio Amazonas.

\section{Material e métodos}

\section{A baCIA HIDROGRÁFICA do RIO MoJU}

A bacia hidrográfica do rio Moju localiza-se no nordeste do estado do Pará, compondo a Região Hidrográfica Costa Atlântica Nordeste, conforme Resolução n. 04/2008 do Conselho Estadual de Recursos Hídricos.

\footnotetext{
13. Kato et al, 2004; Figueiredo, 2009; Ríos-Villamiza et al, 2014

14. Konzen et al, 2015

15. Desta e Lemma, 2017; Hanna et al, 2018

16. Miranda et al, 2009; Gorayeb et al, 2010; Ríos-Villamiza et al, 2011; RíosVillamiza et al, 2014; Silva et al, 2016
}

Em termos político-administrativos faz parte das Mesorregiões do Nordeste e Sudeste Paraense, que agrupam as Microrregiões de Cametá, Tomé-Açu e Tucuruí (Mapa 1) e, segundo seus marcos topográficos de maior variabilidade, encontra-se compartimentada em três setores: Alto Moju - incluída a sub-bacia do Igarapé Marmorana Grande, Médio Moju abrangendo a sub-bacia do rio Cairari e Baixo Moju - juntamente com a sub-bacia do rio Ubá. A segmentação delineada auxilia a avaliação do comportamento hidroquímico das águas, uma vez que isola o Baixo Moju como a área de influência de marés e vulnerável aos efeitos do antropismo decorrentes da proximidade com a Região Metropolitana de Belém.

A bacia do rio Moju é formada por duas unidades geológicas distintas: a bacia sedimentar do Marajó e uma porção do Cinturão Araguaia, representada pelo Grupo Baixo Araguaia; a estrutura tectônica delineada pela rede de drenagem da bacia do rio Moju, demonstra a influência da configuração NW/NNW e NE/ ENE da bacia do Marajó ${ }^{17}$. O Cinturão Araguaia está representado pelo Grupo Baixo Araguaia/Formação Pequizeiro, este consiste de um conjunto de rochas metassedimentares como quartzito, talco xisto, filito e talcoxisto ${ }^{18}$.

A bacia do Marajó é limitada a oeste pelo Arco de Gurupá, a norte pela Bacia da Foz do Amazonas, a leste pela região Marajó Setentrional e a sul pelo Cinturão Orogênico Araguaia (Neoproterozóico), seu preenchimento compreende um pacote de rochas sedimentares depositado desde o Eocretáceo até o Recente ${ }^{19}$.

O contexto sedimentar da bacia do rio Moju é marcado pelos Grupos Itapecuru (argilito siltoso, siltito argiloso, arenito quartzoso muito fino a fino) e Barreiras (fácies carbonáticas - biocalcirruditos, margas, calcilutitos e biohermitos, rochas mistas carbonático-siliciclásticas; e fácies siliciclásticas - argilitos verdes a negros e de amarelados a avermelhados, geralmente laminados, arenitos estratificados e conglomerados sustentados por matriz areno-argilosa); compondo também a Formação Ipixuna (argilitos caulínicos e arenitos finos a grossos, originada em ambiente flúvio-lacustre e fluvial e estuarino) e os Sedimentos Pós-Barreiras ${ }^{20}$.

\footnotetext{
17. Vasquez e Rosa-Costa, 2008

18. Macambira e Ricci, 2013

19. Soares Jr. et al, 2008

20. Santos Junior e Rossetti, 2003; Rossetti, 2006; Vasquez e Rosa-Costa, 2008; Corrêa-Martins et al, 2018
} 
Mapa 1. Localização da Bacia Hidrográfica do rio Moju - PA: aspectos gerais, geológicos e hidrográficos.

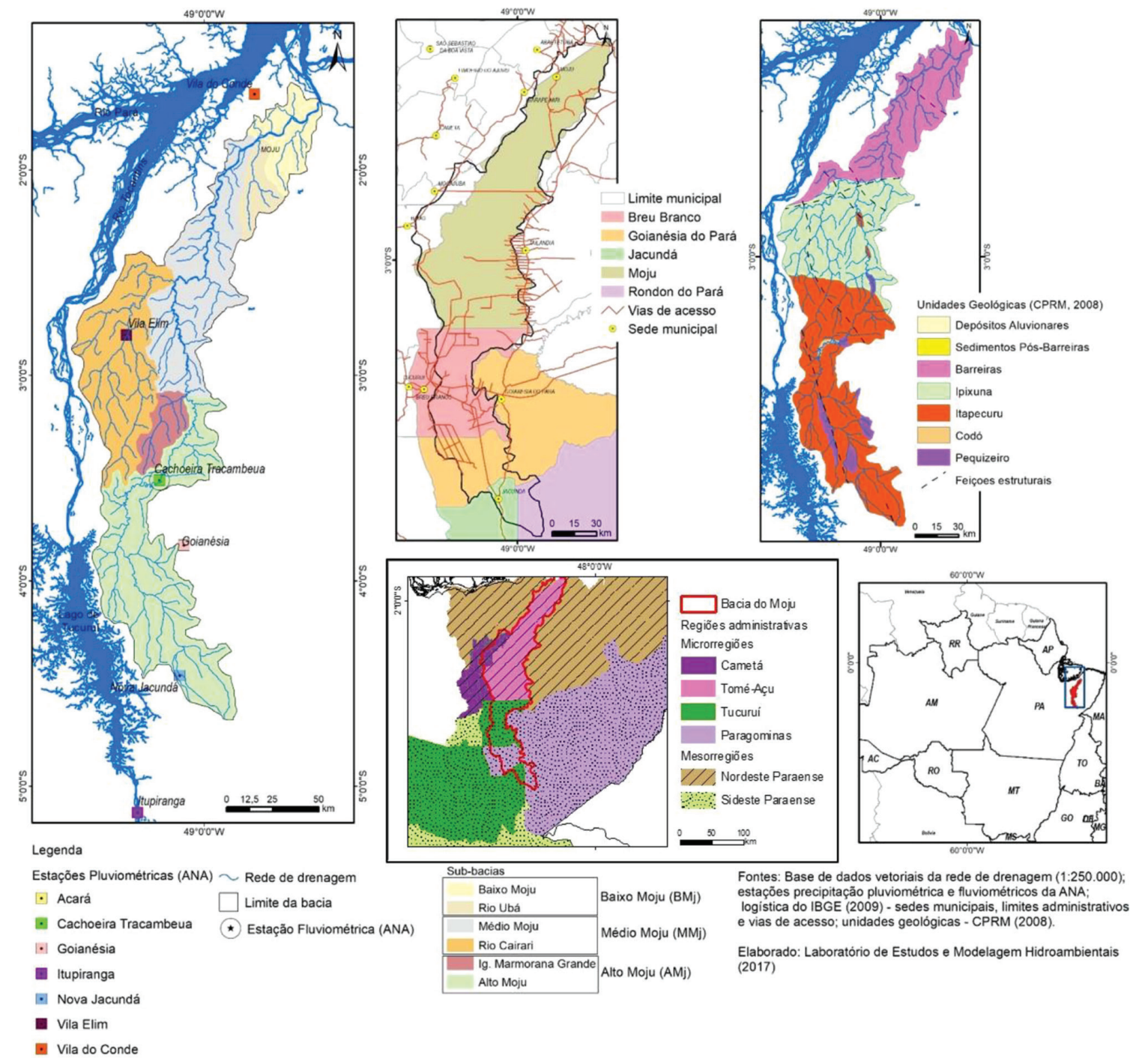

Fonte: Elaborada pelos autores a partir da base cartográfica estruturada em SIG (Sistema de Informação Geográfica).

\section{SISTEMA BASE DE INFORMAÇÕES}

Na elaboração dos documentos adotados para a caracterização da bacia do rio Moju, e sistematizados segundo um Sistema de Informação Geográfica (SIG) estruturado para o trabalho, foram utilizados:

1. Divisão hidrográfica e rede de drenagem oriundas do sistema de codificação OttoBacias, da Agência Nacional de Águas (ANA), na escala 1:250.000, disponibilizada no Sistema Nacional de Informações Sobre Recursos Hídricos (SINGRH), do Governo Federal do Brasil.

2. Modelo digital de elevação extraído da base disponibilizada pela Agência Espacial Norte-Americana (NASA), oriundo da Missão Topográfica Radar Shuttle (SRTM), resolução de 30 metros.

3. Mapa de unidades geomorfológicas elaborado pelo Instituto Brasileiro de Geografia e Estatística
(IBGE), na escala 1:250.000.

4. Mapa de unidades geológicas gerado pela Companhia de Pesquisa de Recursos Minerais (CPRM) do Brasil, na escala 1:1.000.000.

5. Dados hidrometeorológicos: disponibilizados pela ANA na mesma plataforma do SINGRH, referentes a estação pluvio/fluviométrica Cachoeira Tracambeua (código - 3102000; período - 1982 a 2015; chuva, vazão, cotas); e as estações pluviométricas de Vila do Conde (código - 00148011; período - 1981 a 2014), Vila Elim (código - 00249002; período - 1981 a 2014), Goianésia (código - 00349002; período 1986 a 2014) e Nova Jacundá (código - 00449001; período - 1995 a 2014). A escolha dos períodos de análise foi vinculada a melhor consistência registrada dos dados.

6. Cartas de uso e cobertura da terra, projeto TerraClass (anos 2010, 2014), do Instituto Nacional de 
Pesquisas Espaciais (INPE)/Empresa Brasileira de Pesquisa Agropecuária (EMBRAPA) ${ }^{21}$.

7. E mosaico global, PALSAR-2/PALSAR SAR (2017) vinculado ao Mapa Global Floresta/Não Floresta (FNF), com resolução de 25 metros $^{22}$.

A representação adotada simplificou o produto TerraClass, agrupando como "Áreas Alteradas" as classes de uso da terra (agricultura anual, pasto (com solo exposto, limpo, sujo, regeneração com pasto), área urbana, mosaico de ocupações, mineração); como "Áreas Mistas" as categorias denominadas como "Outros" e "Área Não Observada", pela falta de definição das mesmas; e mantendo as unidades "Floresta", "Vegetação Secundária" e "Reflorestamento".

O produto FNF apresenta somente a categoria "Floresta", definida como a floresta natural com área maior que 0,5 hectares e cobertura florestal acima de $10 \%{ }^{23}$; indicando as demais como "Não Floresta", neste caso também denominada como "Áreas Alteradas".

\section{CARACTERIZAÇÃo MORFOMÉTRICA}

A análise morfométrica da rede de drenagem utilizou como base os conceitos apresentados em trabalhos referência ${ }^{23}$, adotando os elementos descritivos de: Perímetro (P), Área (A), Comprimento do maior canal $(\mathrm{Cl})$, Comprimento total dos canais $(\mathrm{Lu})$, Número total dos canais $(\mathrm{Nu})$, Variação altimétrica (altitude máxima mínima) e Diâmetro do círculo de área igual à da bacia $(D c)$. E calculados: Índice de forma equivalente (Kc; Kc $=0,282 P / A 0,5)$; Razão de Circularidade (Rc; $R c=12,57[A$ /P2]); Densidade de drenagem ( $\mathrm{Dd} \mathrm{Km} / \mathrm{Km}^{2} ; \mathrm{Dd}=(\Sigma L u)$ $/ A)$; Coeficiente de manutenção $(\mathrm{Cm} \mathrm{km} / \mathrm{m} ; \mathrm{Cm}=A / \mathrm{Lu})$; Relação de elongação (Re; $R=D c / C l)$; Frequência de canais (Fs n/ $\mathrm{km}^{2} ; \mathrm{Fs}=\mathrm{Nu} / \mathrm{A}$ ); Textura topográfica (Tt; $T t=100,219649+1,115 \log D d)$; e Extensão do percurso superficial (Eps km; Eps=1/2Dd).

\section{ANÁLISE QUALITATIVA DAS ÁGUAS}

Foram definidos 35 pontos equidistantes para coleta de amostragem de água, distribuídos no Alto, Médio e Baixo Moju (Mapa 2). A amostragem teve por base os critérios de: dimensão da bacia - baixo, médio e alto curso; diversidade de ambientes (florestal, áreas agríco-

\footnotetext{
21. Almeida et al, 2016

22. Masanobu Shimada et al, 2014

23. Christofoletti, 1980; Pareta e Pareta, 2012
}

las, áreas urbanas); e representatividade amostral, com uma distribuição mais regular e representativa de cada segmento de curso d'água. A análise do mosaico de uso e cobertura da terra foi base para a definição da amostragem e de sua espacialização.

As coletas de água foram realizadas em setembro de 2015 (período menos chuvoso) e março de 2016 (período mais chuvoso) em pontos distribuídos ao longo da bacia. Para cada coleta foi determinado em campo, em amostras não filtradas, as seguintes variáveis físico-químicas e organolépticas: $\mathrm{pH}$, condutividade elétrica (CE), sólidos totais dissolvidos e temperatura.

Os procedimentos adotados para preservação das amostras e metodologia de análise obedeceram aos critérios e rotinas já adotados e sistematizados pelo Laboratório de Análises Químicas da Universidade Federal do Pará, com base no "Standard Methods for the Examination for Water and Wastewater" "24 Para a determinação da concentração dos principais cátions e ânions, em amostras filtradas em membrana de $0,45 \mu \mathrm{m}$, foi utilizada a cromatografia iônica. $\mathrm{O}$ equipamento utilizado foi um cromatógrafo de íons Dionex-DX120.

Para a análise de cátions utilizou-se coluna catiônica (CSRS ULTRA-CS12A Dionex), eluente 20Mm MSA (Ácido Metanosulfônico) e fluxo $1,0 \mathrm{~mL} \mathrm{~min}^{-1}$; dos ânions foi adotada uma coluna aniônica (ASRS ULTRA-AS14 Dionex), como eluente a solução $3,5 \mathrm{mM} \mathrm{Na}_{2} \mathrm{CO}_{3} / 1,0 \mathrm{mM}$ $\mathrm{NaHCO}_{3}$ e fluxo $1,2 \mathrm{~mL} \mathrm{~min}^{-1}$.

Os softwares utilizados para o tratamento dos dados hidroquímicos foram: Statistica 7 para elaboração de estatística (estatística básica e distribuição sequencial); e AquaChem 3.70 para análise dos dados hidroquímicos (diagramas de caracterização e classificação das águas: Stiff e Piper).

\section{Resultados e discussão}

Como parte dos produtos gerados pela base cartográfica sistematizada em SIG, e que compõe a análise morfométrica elaborada para a bacia do rio Moju, é apresentada sua caracterização em unidades de relevo ${ }^{25}$, segundo as associações individualizadas e que melhor descrevem sua dinâmica.

Observa-se que se trata de uma bacia de $5^{\mathrm{a}}$ ordem (segundo a escala de análise 1:250.000), com tendência ao escoamento, tanto pelo domínio do padrão treliça-pa- 
Mapa 2. Identificação dos locais de amostragem.
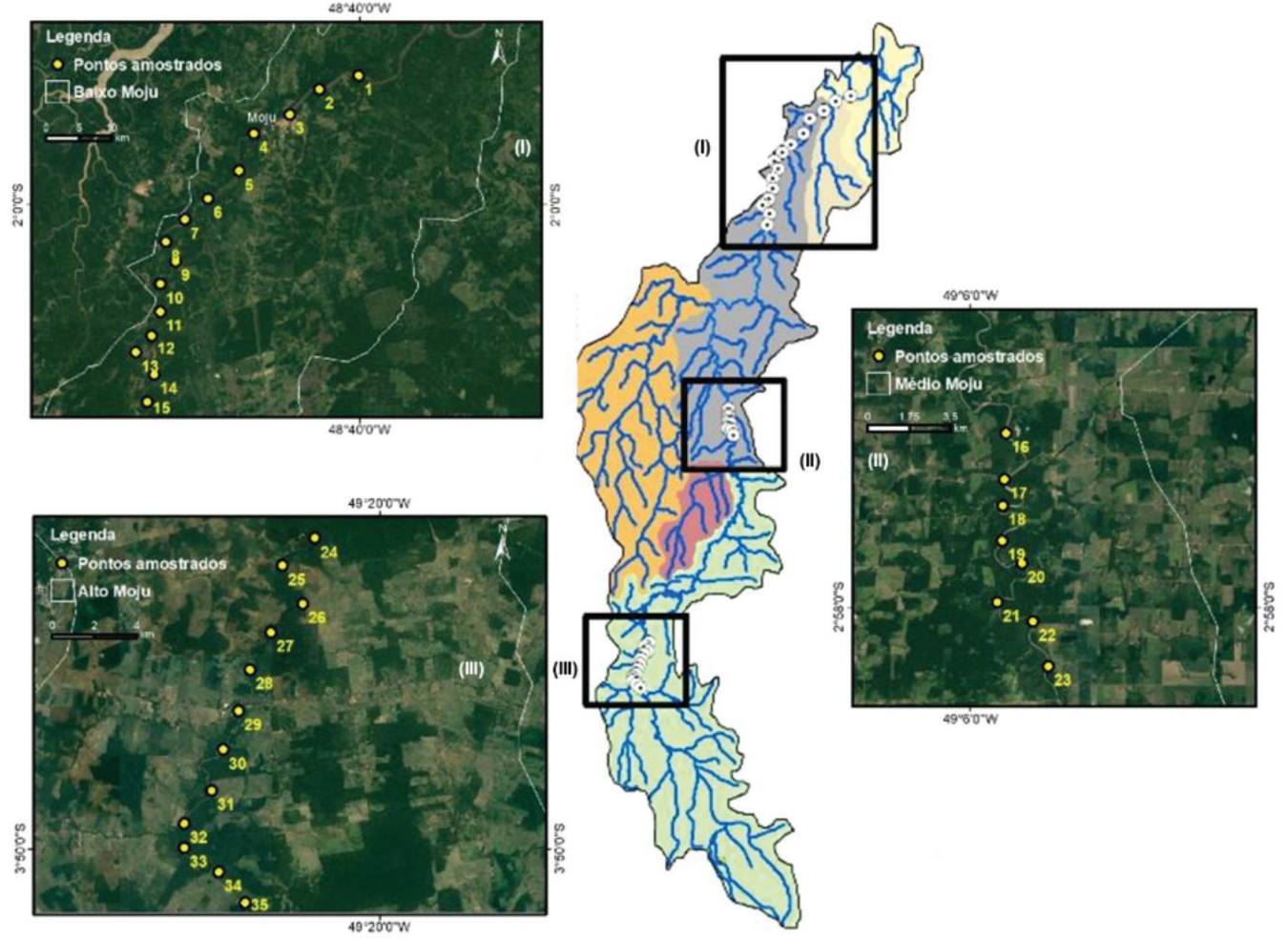

Fonte: Imagens Maxar Technologies, Google Earth Pro.

ralelo, quanto pelas relações observadas entre seus coeficientes morfométricos. Onde são destacadas as formas em dissecação convexa e tabulares, pediplanos e áreas de acumulações de planície fluvial e de inundação ${ }^{26}$. As maiores altitudes encontram-se no Alto Moju, sendo superiores a $260 \mathrm{~m}$; e as menores na sua foz com os rios Acará e Guamá (Mapa 3).

O padrão alongado da bacia gera formas de relevo de dissecação formadas por vertentes convexas, topos tabulares e vales abertos. Próximo à foz o vale se torna mais expressivo (aberto) e aparecem formas arredondadas, onde se observa uma maior largura da planície de inundação.

As unidades de relevo caracterizadas foram (Mapa 3): (Unidade 1) vales abertos, localmente associados a formas de dissecação convexa, áreas de acumulação e planícies de inundação, caracterizando as mais baixas declividades da bacia, o padrão de drenagem é tipicamente paralelo-treliça; (Unidade 2) topos tabulares com vertentes côncavo-convexas, associados a vales abertos e declividades que variam de médias a baixas, o padrão de drenagem é paralelo-treliça, localmente angular; (Unidade 3) topos tabulares, vales fechados e abertos, com vertentes convexas em áreas de média a alta declividades, o padrão de drenagem é paralelo-treliça, localmente angular; e (Unidade 4) topos arredondados, vales fechados e vertentes côncavas, onde dominam as mais altas declividades da bacia, o padrão de drenagem é paralelo-treliça.

A análise do comportamento do escoamento superficial pelos coeficientes morfométricos ${ }^{27}$ (Figura 1), indicou formas que se afastam da circularidade (boa correlação entre $\mathrm{Kc}, \mathrm{Cl}$ e Lu) e identificam o predomínio de estruturas de dissecação (boa correlação entre Rc e Nu; e superior a 0,6 para Rc e variação altimétrica, Fs com Tt e Eps). O Baixo Moju apresenta tendência diferencial, com maior frequência de acumulação. E a sequência Médio e Alto Moju corresponde ao maior potencial de escoamento. Eps e Kc foram os parâmetros de maior variabilidade, os demais obtiveram uma menor variação em torno na média, demonstrando a resposta mais homogênea do conjunto das sub-bacias.

\section{Uso E Cobertura da Terra}

Para melhor compreender as variações sobre o comportamento natural relativo à qualidade das águas, a partir do verificado no contexto geológico-geomorfológico da bacia, foram avaliadas as formas de antropismo 
Mapa 3. Altimetria, geomorfologia geral e unidades de relevo segundo a divisão em sub-bacias da bacia hidrográfica do rio Moju.
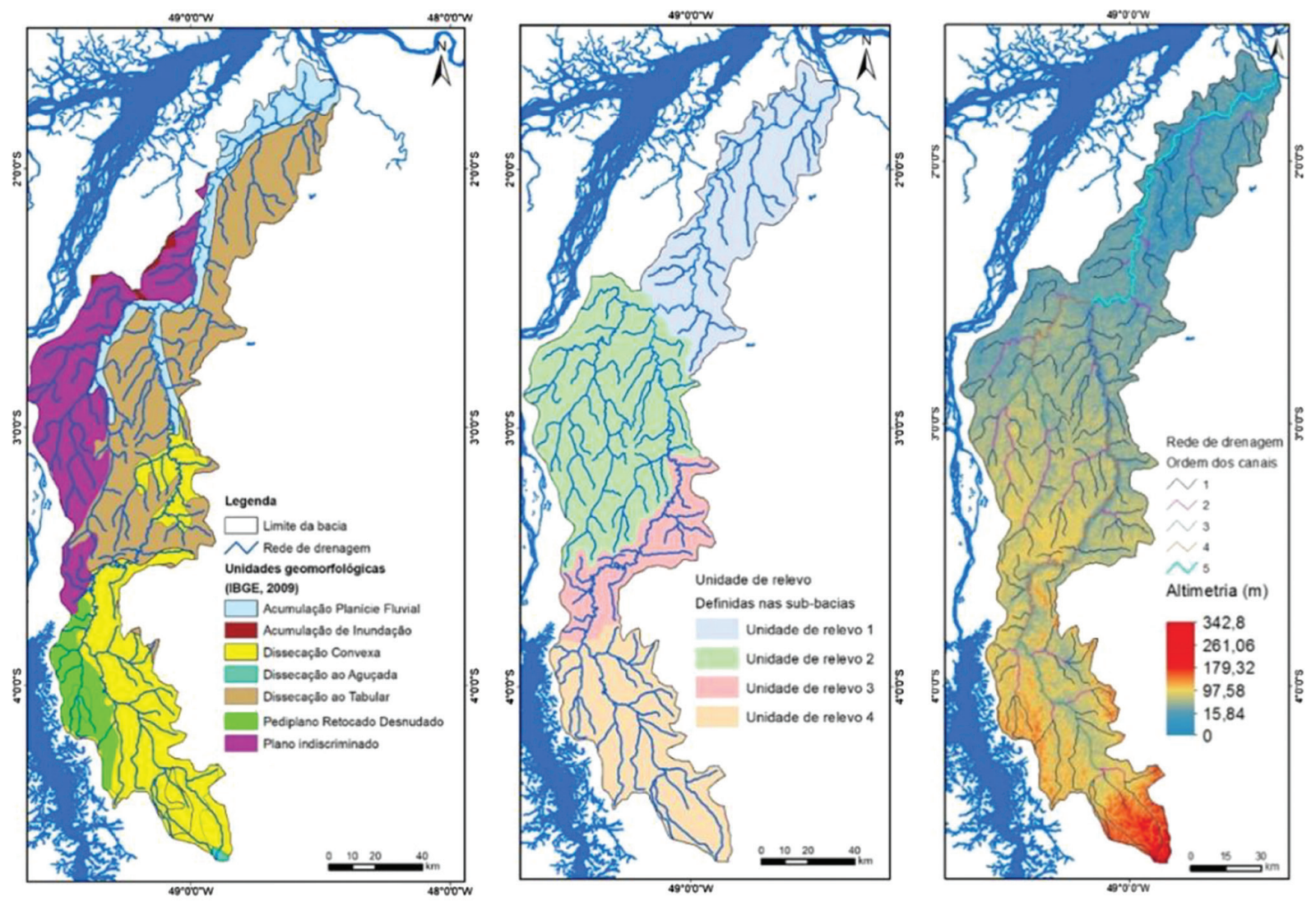

Fontes: Altimetria - Imagens SRTM. Dados vetoriais de informação logística e Geomorfologia do IBGE (2009); rede de drenagem na escada 1:250.000 da ANA. Unidades de relevo - definidas neste trabalho.

Elaborado: Laboratório de Estudos e Modelagem Hidroambientais (2018).

Fonte: Elaborada pelos autores a partir da base cartográfica estruturada em SIG.

existentes e sua distribuição espacial e influência sobre os sistemas hídricos.

Os produtos avaliados são relativos ao uso e cobertura da terra para a bacia do rio Moju, sendo que, por representarem classificações diferenciais foram apenas analisados quanto ao aspecto espacial da bacia (Mapa 4).

$O$ gerado pelo TerraClass/2010 e $2014^{28}$ tem maior detalhamento de classes, demonstrando o Baixo e Médio Moju e a sub-bacia do rio Cairari com maior área de cobertura vegetal incluindo as classes "Floresta" e "Vegetação Secundária".

Em termos percentuais de 2010 para 2014 na classe "Floresta" ocorreu uma redução de -1,39 (38,60\%/37,21\%), o mesmo para "Vegetação Secundária", de -1,80 (23,21\%/21,41\%); a categoria "Áreas Alteradas" obteve um incremento de $+2,26(31,16 \% / 33,42 \%)$, dentre as demais classes de menor representatividade, a categoria "Áreas Mistas" $(6,56 \% / 7,53 \%)$ obteve um incremento $(+0,97)$ e de "Reflorestamento" $(0,46 \% / 0,42 \%)$ uma redução $(-0,04)$.
O produto Forest/Non-Forest (FNF) de 2017, que traz apenas a categoria de classificação "com ou sem floresta"29 , modifica de forma significativa o quadro da sub-bacia do rio Cairari indicando que esta pode estar com parte de sua vegetação secundária sendo identificada como áreas tipicamente alteradas. Isto pode ser observado quando se identificam os percentuais: a classe "Floresta" está em 53,84\% da bacia e a "Não Floresta" em 46,16\% em 2017; considerando a soma entre "Floresta" e "Vegetação Secundária" para o ano de 2014, a cobertura vegetal da bacia seria de $58,62 \%$, e das demais classes de 41,38\%; logo, registra-se uma diferença de $4,78 \%$, como sendo a faixa de divergência entre as duas classificações.

É importante ressaltar que o INPE classifica as áreas de plantação de dendê como vegetação secundária, sendo consideradas áreas que, após a supressão total da vegetação florestal, encontram-se em processo avançado de regeneração da vegetação arbustiva e/ou arbórea ou 
Figura 1. Relações morfométricas caracterizadas.

Parâmetros

\begin{tabular}{|c|c|c|c|c|c|c|c|c|c|c|c|}
\hline Unidades & $P(\mathrm{~km})$ & \multicolumn{2}{|r|}{$A\left(\mathrm{~km}^{2}\right)$} & \multicolumn{2}{|c|}{$\begin{array}{c}\mathrm{Cl} \\
(\mathrm{km})\end{array}$} & \multicolumn{2}{|c|}{$L u(k m)$} & $\mathrm{Nu}$ & $\begin{array}{c}\text { Amáx- } \\
\text { Amin } \\
(m)\end{array}$ & \multicolumn{2}{|c|}{$D c(m)$} \\
\hline Rio Moju & \multicolumn{2}{|c|}{1079,80} & 15662,10 & \multicolumn{2}{|c|}{546,50} & \multicolumn{2}{|c|}{2701,11} & 224 & 342,80 & \multicolumn{2}{|c|}{141,25} \\
\hline BMJ & 191,59 & \multicolumn{2}{|c|}{1205,47} & \multicolumn{2}{|c|}{47,42} & \multicolumn{2}{|c|}{190,53} & 21 & 250,80 & \multicolumn{2}{|c|}{39,19} \\
\hline RUb & 140,21 & \multicolumn{2}{|r|}{695,19} & \multicolumn{2}{|c|}{55,32} & \multicolumn{2}{|c|}{85,12} & 5 & 259,70 & \multicolumn{2}{|c|}{29,76} \\
\hline $\mathrm{MMj}$ & 409,41 & & 3804,24 & \multicolumn{2}{|c|}{211,63} & \multicolumn{2}{|c|}{672,07} & 57 & 285,40 & \multicolumn{2}{|c|}{69,61} \\
\hline $\mathrm{RCr}$ & \multicolumn{2}{|l|}{353,66} & 3649,68 & 158 & & 612,5 & & 51 & 174,30 & & 8,19 \\
\hline IMG & 135,45 & & 716,33 & 54, & & 137,6 & & 13 & 132,00 & & 21 \\
\hline AMJ & 618,05 & & 5591,20 & 287 & & 1003,2 & & 77 & 342,80 & & \\
\hline Unidades & $K c$ & $R c$ & $\begin{array}{r}D \\
(\mathrm{Km}\end{array}$ & & & $\begin{array}{l}m \\
\mathrm{a} / \mathrm{m})\end{array}$ & $R e$ & & $\begin{array}{l}F_{S} \\
\left.\mathrm{a} / \mathrm{km}^{2}\right)\end{array}$ & $T t$ & $E p$ \\
\hline Rio Moju & 2,43 & 0,17 & 0 , & & & 8,39 & 0,26 & & 014 & 0,23 & 2,90 \\
\hline BMJ & 1,56 & 0,41 & 0,1 & & & 6,96 & 0,83 & & 0,017 & 0,21 & 3,16 \\
\hline RUb & 1,50 & 0,44 & 0,1 & & & 7,03 & 0,54 & & 0,007 & 0,16 & 4,08 \\
\hline $\mathrm{MMj}$ & 1,87 & 0,29 & 0 , & & & 0,46 & 0,33 & & 0,015 & 0,24 & 2,83 \\
\hline $\mathrm{RCr}$ & 1,65 & 0,37 & 0 , & & & 95 & 0,43 & & 14 & 0,23 & 2,98 \\
\hline IMG & 1,43 & 0,49 & 0,1 & & & 05,97 & 0,55 & & 0,018 & 0,26 & 2,60 \\
\hline AMJ & 2,33 & 0,18 & 0,1 & & & 73,25 & 0,29 & & 0,014 & 0,24 & 2,79 \\
\hline
\end{tabular}

Variação em torno dos valores médios

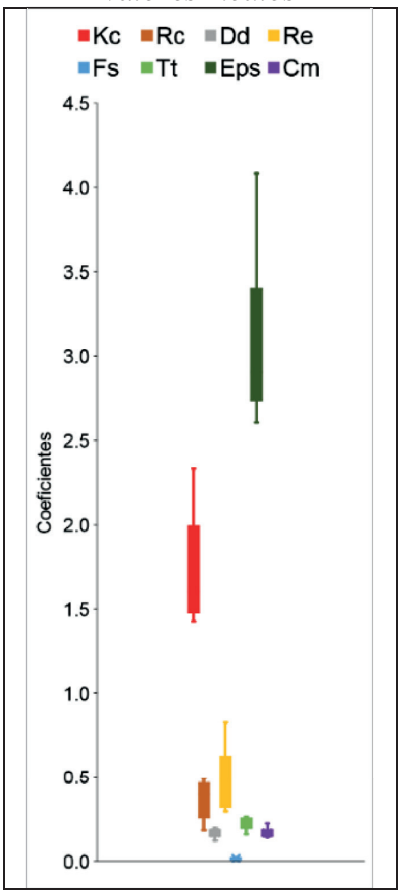

\begin{tabular}{cl}
\hline $\begin{array}{c}R^{2} \\
\text { (Correlação } \\
\text { Linear) }\end{array}$ & \multicolumn{1}{c}{ Parâmetros } \\
\hline 0,89 & $\begin{array}{l}\text { Índice de forma equivalente de } \\
\text { forma (Kc) x Comprimento do } \\
\text { maior canal (Cl) }\end{array}$ \\
\hline 0,86 & $\begin{array}{l}\text { Índice de forma equivalente de } \\
\text { forma (Kc) x Comprimento } \\
\text { total dos canais (Lu) }\end{array}$ \\
\hline 0,89 & $\begin{array}{l}\text { Razão de Circularidade (Rc) } \mathrm{x} \\
\text { Número total dos canais }\end{array}$ \\
\hline 0,61 & $\begin{array}{l}\text { Razão de Circularidade (Rc) } \mathrm{x} \\
\text { Variação altimétrica }\end{array}$ \\
\hline 0,66 & $\begin{array}{l}\text { Frequência de canais (Fs) } \mathrm{x} \\
\text { Textura topográfica (Tt) }\end{array}$ \\
\hline 0,71 & $\begin{array}{l}\text { Frequência de canais (Fs) } \mathrm{x} \\
\text { Extensão do percurso } \\
\text { superficial (Eps) }\end{array}$ \\
\hline
\end{tabular}

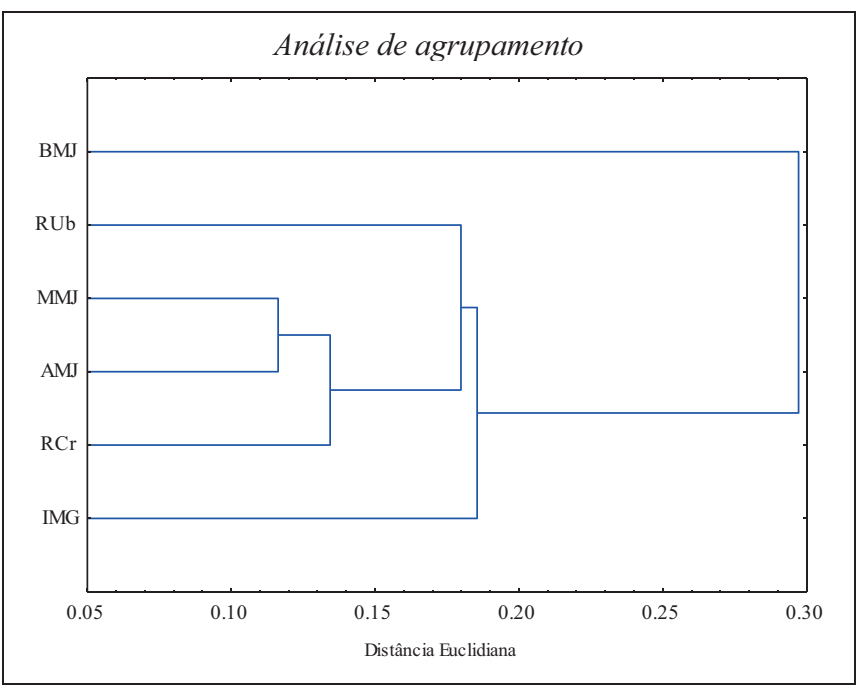

Onde: Perímetro - P $(\mathrm{m})$; Área - A $\left(\mathrm{km}^{2}\right)$; Comprimento do maior canal - $\mathrm{Cl}(\mathrm{km})$; Comprimento total dos canais - Lu ( $\left.\mathrm{km}\right)$; Número total dos canais (Nu); Variação altimétrica: Amáx-Amin (m); Diâmetro do círculo de área igual à da bacia - Dc (km); Índice de forma equivalente - Kc; Razão de Circularidade - Rc; Densidade de drenagem - Dd (Km/Km²); Coeficiente de manutenção - $\mathrm{Cm}(\mathrm{km} / \mathrm{m})$; Relação de elongação (Re); Frequência de canais $\left(\mathrm{n} / \mathrm{km}^{2}\right)$; Textura topográfica - Tt; Extensão do percurso superficial - Eps. Baixo Moju (BMJ); Rio Ubá (RUb); Médio Moju (MMj); Rio Cairari (RCr); Ig. Marmorana Grande (IMG); Alto Moju (AMJ).

Fonte: Elaborada pelos autores, com parte do processamento morfométrico.

que foram utilizadas para a prática de silvicultura ou agricultura permanente nativa ou exóticas ${ }^{30}$.

Em termos de uso econômico do território, a bacia concentra atividades vinculadas ao extrativismo vegetal e à agropecuária, sendo o maior percentual da produção observado no município de Moju ${ }^{31}$, onde tam-

\footnotetext{
30. Coutinho et al, 2013

31. Ferreira et al, 2016
}

bém se destaca o cultivo do dendê com área de plantio superior a 16000 hectares $^{32}$. A criação de animais (representatividade do bovino) e a atividade de aquicultura ocorrem em todos os municípios componentes da bacia.

No Alto Moju ambas as classificações mostraram similaridade de comportamento, indicando a manu- 
Mapa 4. Cartas de uso e cobertura da terra da bacia hidrográfico do rio Moju.
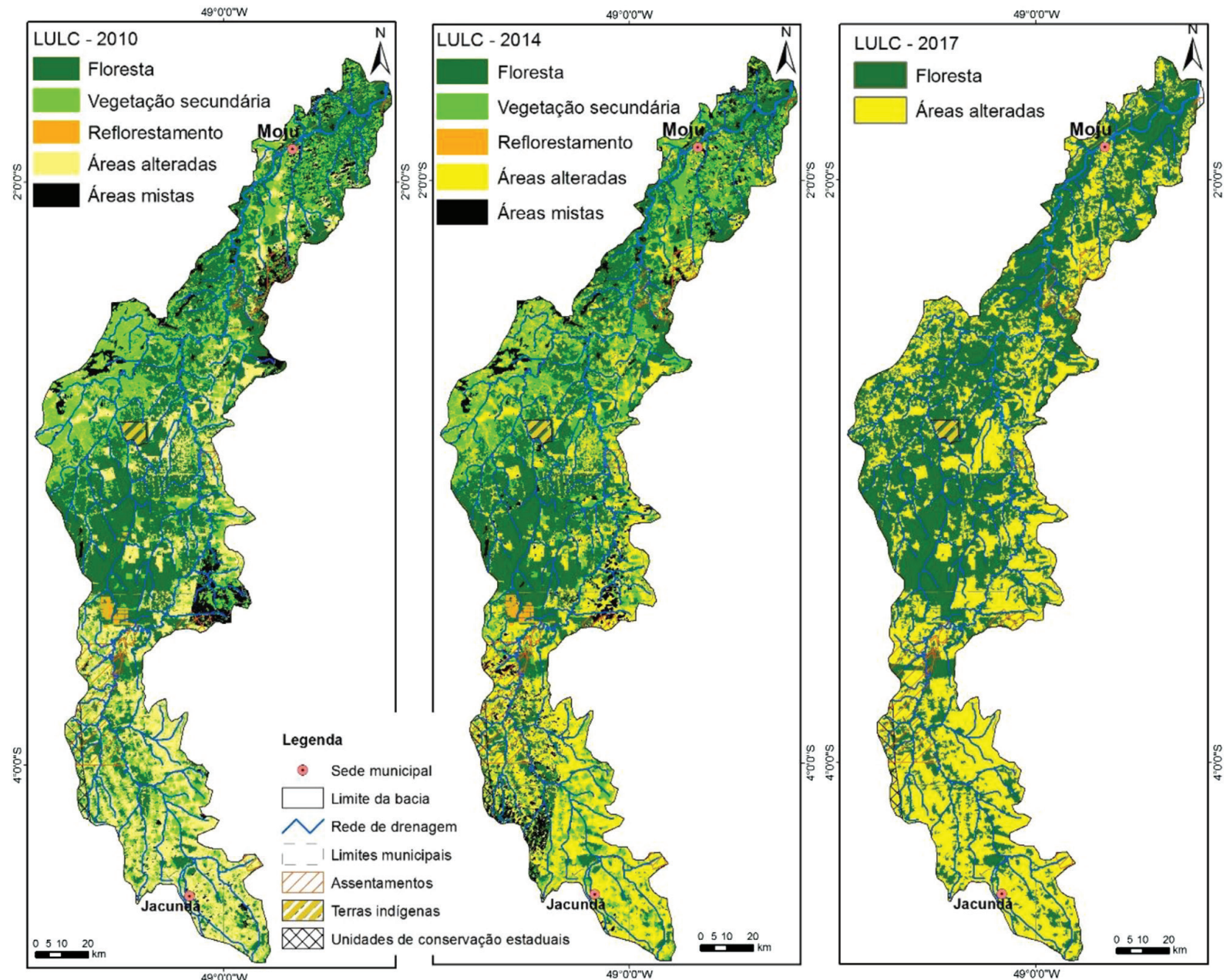

Fontes: Base de dados vetoriais de: rede de drenagem (1:250.000), logistica do IBGE (2009) - sedes municipais, limites administrativos e vias de acesso. LULC - Land Use Land Cover - 2010, 2014: Projeto TerraClass INPE/EMBRAPA), Almeida et al. (2016); 2017 - Global PALSAR-2/PALSAR Forest/Non-Forest Map, Earth Engine Data Catalog, Masanobu Shimada et al.(2014).

Elaborado: Laboratorio de Estudos e Modelagem Hidroambientais (2019).

Fonte: Elaborada pelos autores a partir da base cartográfica estruturada em SIG.

tenção da área alterada de 2010 a 2017. Na bacia do rio Moju as formas de uso e a cobertura são determinantes para o estado do ambiente natural e da qualidade da água e de como esta chegará aos usuários, uma vez que na bacia encontram-se duas sedes municipais além de diversas localidades que demandam por água para consumo humano. As mudanças no uso e cobertura da terra influenciam a diversidade biológica ${ }^{33}$, o clima $^{34}$ e os ciclos biogeoquímicos e da água ${ }^{35}$. E as características físico-químicas das águas do rio Moju possuem variações que podem ser condicionadas por estes fatores.

\footnotetext{
33. Sala et al, 2000; Oki e Kanae, 2006

34. Niraula et al, 2015

35. Varol et al, 2012; Hanna et al, 2018
}

\section{ANÁlise DE QuAlidade DA ÁGUA}

No processo de avaliação da qualidade da água do rio Moju foram considerados como condicionantes: as características hidrológicas da região, a sazonalidade do período chuvoso e menos chuvoso e a variabilidade do comportamento das vazões.

O período menos chuvoso é marcante de agosto a outubro; e o chuvoso, no trimestre fevereiro-março-abril (Gráfico 1a).

A vazão é representativa da transição entre o Alto e o Médio Moju, assim não recebe a contribuição da sub-bacia do rio Cairari $\left(3.649,68 \mathrm{~km}^{2}\right)$, logo se considerou este efeito nas avaliações, ou seja, a entrada de um volume de água de diluição/dissipação significativo em direção à foz. 
Gráfico 1. Distribuição sazonal de (a) precipitação pluviométrica e (b) precipitação pluviométrica, vazão e cotas (Estação da Cachoeira Tracambeua 3102000) na bacia do rio Moju.

(a)

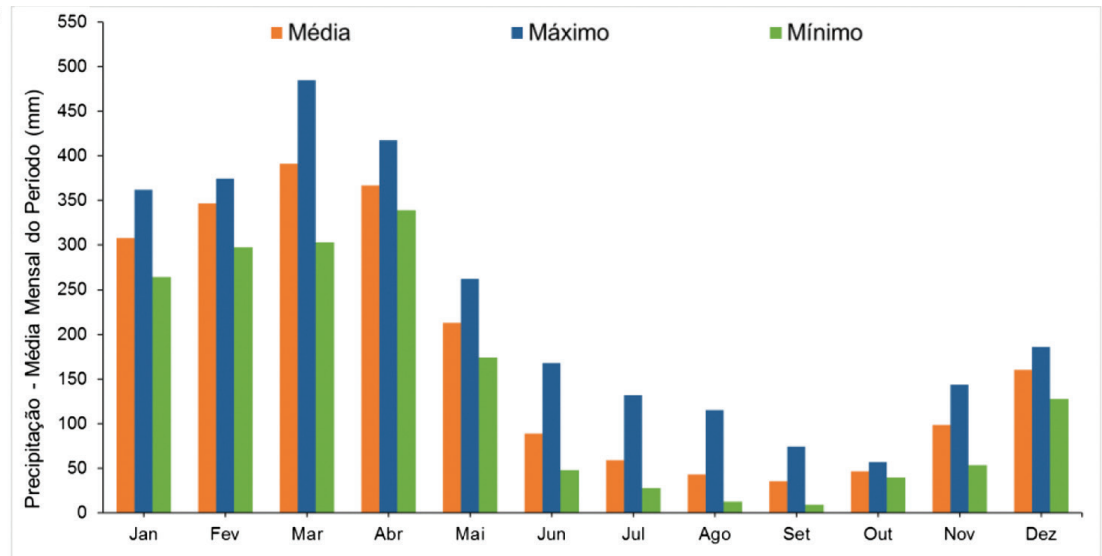

(b)

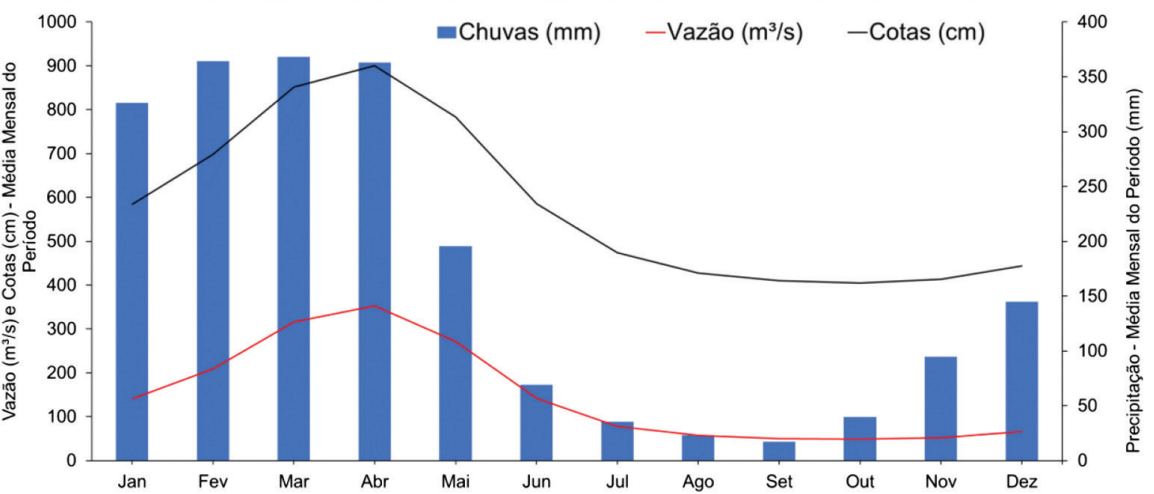

Fonte: Elaborado pelos autores a partir dos dados pluviométricos e fluviométricos da ANA.

Considerando a vazão específica média ${ }^{36}$ (relação área x vazão) a sub-bacia do rio Cairari poderia representar um incremento superior a $60 \%$ de vazão, admitindo os valores máximos dos períodos chuvoso e menos chuvoso.

É observada uma variação (média mensal do período) de cerca de $86 \%\left(353 \mathrm{~m}^{3} / \mathrm{s}\right.$ e $\left.48 \mathrm{~m}^{3} / \mathrm{s}\right)$ entre o máximo e o mínimo de vazões (redução de $55 \%$ no nível das águas) e $95 \%$ de chuvas ( $368 \mathrm{~mm} / 17 \mathrm{~mm}$ ) (Gráfico $1 \mathrm{~b}$ ). Somente quanto às chuvas, a variação no Baixo Moju (Estação de Vila do Conde) chega a 87\% $(339 \mathrm{~mm} / 44$ $\mathrm{mm}$ ) e no Médio Moju (Estação Vila Elim) a cerca de $91 \%$ (484 mm/44 mm).

Como o ponto de medição da vazão está refletindo o comportamento da cabeceira, é verificado que não existe atraso entre o pico das chuvas e das vazões na região. Admitindo estas condições, as coletas voltadas para a análise qualitativa das águas foram feitas no leito do rio Moju, contemplado as três segmentações propostas: alto, médio e baixo curso do rio Moju.

Tendo como base o previsto na Resolução do Conselho Nacional de Meio Ambiente (CONAMA) nº 357, de 17 de março de 2005, o rio Moju, pela ausência de enquadramento próprio, deve ser considerado como um rio de Classe 2 (Art. 42). Quanto aos parâmetros avaliados foi observada alteração apenas no pH (recomendado entre 6 e 9), porém o padrão das águas que drenam a região amazônica, comumente é encontrado na faixa das águas ácidas ${ }^{37}$. Esta resolução, por ser padronizada para todo o país, não contempla particularidades regionais ou comportamentos esperados pelo background local ${ }^{38}$.

Os resultados da campanha correspondente ao período menos chuvoso mostraram que as concentrações dos parâmetros físico-químicos sofreram variações ao longo dos pontos coletados: a temperatura oscilou de 28,3 a $37,7^{\circ} \mathrm{C}$; $\mathrm{pH}$ de 5 a 5,72; $\mathrm{CE}$ de 12 a $20,7 \mu \mathrm{S} / \mathrm{cm}$; e STD de 6 a $10 \mathrm{mg} / \mathrm{L}$. Ocorrendo uma maior regularidade entre o Alto e Médio Moju e variação no Baixo Moju.

Em relação às concentrações de cátions e de ânions, também foram verificadas variações: $\mathrm{Cl}^{-}$de 1,32 a 2,92 $\mathrm{mg} / \mathrm{L} ; \mathrm{NO}_{3}$ - de 0,25 a $1,29 \mathrm{mg} / \mathrm{L} ; \mathrm{SO}_{4}^{2-}$ de 0,15 a $0,65 \mathrm{mg} / \mathrm{L}$; $\mathrm{Na}^{+}$de 0,91 a 2,06 mg/L; $\mathrm{K}^{+}$de 0,19 a $1,76 \mathrm{mg} / \mathrm{L} \mathrm{Mg}^{2+} \mathrm{de}$ 0,01 a $0,11 \mathrm{mg} / \mathrm{L} ; \mathrm{Ca}^{+} \mathrm{de} 0,02$ a $0,08 \mathrm{mg} / \mathrm{L}$.

\footnotetext{
37. Silva et al, 2016

38. Aprile e Darwich, 2009; Umbuzeir et al, 2010
} 
A Tabela 1 ilustra a estatística básica dos parâmetros Temperatura ( $\left.C^{\circ}\right)$, pH, Turbidez (UNT), Condutividade $(\mu \mathrm{S} / \mathrm{cm})$ e Sólidos Totais Dissolvidos - STD $(\mathrm{mg} / \mathrm{L})$; e o aspecto de maior regularidade entre o Alto e Médio Moju e variação no Baixo Moju.

O período chuvoso indicou valores para temperatura de 27,5 a $28,9{ }^{\circ} \mathrm{C} ; \mathrm{pH}$ de 5 a 6,36; CE de 15,6 a 21,7 $\mu$ s/ $\mathrm{cm}$; e STD de 7 a $10 \mathrm{mg} / \mathrm{L}$. As concentrações de cátions e ânions foram para: $\mathrm{Cl}^{-}$de 1,48 a 2,99 mg/L; $\mathrm{NO}_{3}^{-}$de 0,14 a $0,68 \mathrm{mg} / \mathrm{L} ; \mathrm{SO}_{4}{ }^{2-}$ de 0,11 a $0,29 \mathrm{mg} / \mathrm{L} ; \mathrm{Na}^{+}$de 0,77 a 1,51 $\mathrm{mg} / \mathrm{L} ; \mathrm{K}^{+}$de 0,47 a $2,37 \mathrm{mg} / \mathrm{L} ; \mathrm{Mg}^{2+}$ de 0,04 a $0,17 \mathrm{mg} / \mathrm{L}$; $\mathrm{Ca}^{+}$de 0,04 a $0,17 \mathrm{mg} / \mathrm{L}$.

Tanto no período chuvoso como no período menos chuvoso, não ocorreram grandes alterações no pH nos segmentos de bacia. A Turbidez, por sua vez, mostrou valores crescentes do Baixo Moju para o Alto Moju. A Condutividade Elétrica acompanhou a Turbidez de forma mais suave, aumentando em direção ao Alto Moju (Gráfico 2).

Os parâmetros morfométricos indicam que os processos de dissecação são potencialmente favorecidos no Alto Moju, acarretando desta forma a produção de sedimentos, e que esta região coincide com a maior representatividade de áreas alteradas na bacia, principalmente relacionadas ao setor produtivo (agropecuário) e mosaico de ocupações.

De acordo com o diagrama de Piper, as amostras de água nas três sub-bacias, durante o período menos chuvoso, são caracterizadas como águas sódio cloretadas (Gráfico 3a). No decorrer do período chuvoso não houve alteração no tipo de água, porém na transição entre o Baixo e o Médio Moju (P-13 a P-29) se observou uma tendência na elevação da concentração de $\mathrm{Ca}^{2+}$, caracterizando, assim, águas cloretadas cálcicas (Gráfico 3b).

Ao longo da bacia do rio Moju, ocorre intensa atividade de dendeicultura, portanto, é provável que a presença de $\mathrm{Ca}^{2+}$ na água superficial pode ser resultado da prática da calagem, muito usada para correção da acidez do solo. Estudos consideram que as mudas de palma de óleo são tolerantes à acidez do solo, entretanto, o uso de calcário, fonte de cálcio e de magnésio, resultaria em benefícios como aumento da disponibilidade de nutrientes no solo e da eficiência dos fertilizantes ${ }^{39}$.

Os diagramas de Schoeller das águas das três sub-bacias também fornecem dados importantes sobre a influência do uso da terra na qualidade das águas do rio Moju (Gráfico 4). No Baixo Moju, durante o período menos chuvoso, as águas têm suas características modifi-

\footnotetext{
39. Cristancho et al, 2011; Franzini et al, 2012
}

cadas. A contribuição de $\mathrm{Ca}^{2+}$, provavelmente oriunda do escoamento superficial cessa e ocorre um espalhamento, no que diz respeito ao $\mathrm{Mg}^{2+}, \mathrm{SO}_{4}^{2-}$ e $\mathrm{NO}_{3}$.

No Médio Moju no período chuvoso ocorre pouca mistura e no menos chuvoso não há contribuição nenhuma de $\mathrm{Ca}^{2+}$. No Alto Moju, no período chuvoso a mistura no que diz respeito aos cátions é reduzida, contudo, para $\mathrm{SO}_{4}{ }_{4}^{2-}$ e $\mathrm{NO}_{3}{ }_{3}^{-}$o comportamento varia. No período menos chuvoso percebe-se um espalhamento relativo ao $\mathrm{Ca}^{2+} \mathrm{e}$ ao $\mathrm{Mg}^{2+}$ sugerindo misturas com diversas fontes. A Mapa 5 apresenta a mesma distribuição associada às formas de uso da terra.

É importante separar a avaliação Alto-Médio Moju do Baixo Moju, pois este último contempla a ação das marés. Como a amostragem foi anterior à contribuição da sub-bacia do rio Cairari, o efeito da vazão é praticamente o mesmo em todo o segmento Alto-Médio Moju, o que permite identificar que a variação nos períodos (chuvoso e menos chuvoso) e entre estes, é produto do efeito da diluição e das possíveis contribuições das modificações de uso e cobertura da terra.

A amostragem do Alto Moju é paralela a uma área de assentamento rural, tendo como unidade geológica principal formadora, os sedimentos do Grupo Itapecu$\mathrm{ru}$, com forte presença de caulinita $\left(\mathrm{Al}_{2} \mathrm{O}_{3} \cdot 2 \mathrm{SiO}_{2} \cdot 2 \mathrm{H}_{2} \mathrm{O}\right)$, esmectita $\left(\mathrm{Al}_{2} \mathrm{Si}_{4} \mathrm{O}_{10}(\mathrm{OH})_{2} \cdot \mathrm{nH}_{2} \mathrm{O}\right)$, quartzo $\left(\mathrm{SiO}_{2}\right)$ e microclínio $\left(\mathrm{KAlSi}_{3} \mathrm{O}_{8}\right)^{40}$, que pode exemplificar a manutenção do comportamento similar do $\mathrm{Na}+\mathrm{K}$ no período chuvoso e menos chuvoso. A igual persistência do cloreto $\left(\mathrm{Cl}^{-}\right)$indica a presença proveniente das águas das chuvas e a contribuição de nitrato $\left(\mathrm{NO}_{3}^{-}\right)$da interferência do efeito de queimadas em áreas florestais ${ }^{41}$. De forma geral, a região do Alto-Médio Moju por ser marcada pelo intenso uso agropecuário (a classe "Áreas Alteradas" em 2014 representa 31,43\% nesta região) pode intervir de várias formas na variabilidade local destes parâmetros, conforme atestado pela componente turbidez.

Em 10 hectares de dendê pode-se encontrar entre 1.430 a 1.600 palmeiras, onde é utilizado basicamente Nitrogênio, Fósforo e Potássio (NPK) em torno de 9,6 ton/ano, sendo que cada planta adulta recebe cerca de 6 $\mathrm{kg} / \mathrm{ano}$, além disto uma palmeira pode receber por ano de 3 a 4 aplicações de um agrotóxico a base de herbicida (glifosato) para limpeza ao seu redor contra o avanço de outras espécies vegetais ${ }^{42}$.

\footnotetext{
40. Corrêa-Martins et al, 2018

41. Marques et al, 2010

42. Nahum e Santos, 2013
} 
Tabela 1. Estatística básica aplicada aos parâmetros hidroquímicos: (1) período menos chuvoso; (2) período chuvoso. Média (Md), Mediana (Mda), Mínimo (min), Máximo (Max); Percentil (P); Variância (Var); Desvio Padrão (Dp).

\begin{tabular}{|c|c|c|c|c|c|c|c|c|}
\hline Alto Moju & Md & Mda & Min & Max & $\mathrm{P} 25 \%$ & P75\% & Var & Dp \\
\hline Temperatura $(1)\left({ }^{\circ} \mathrm{C}\right)$ & 31,31 & 30,85 & 28,30 & 35,70 & 29,35 & 33,35 & 7,255 & 2,694 \\
\hline Temperatura $(2)\left({ }^{\circ} \mathrm{C}\right)$ & 28,46 & 28,60 & 27,50 & 28,90 & 28,05 & 28,80 & 0,204 & 0,453 \\
\hline $\mathrm{pH}(1)$ & 5,53 & 5,53 & 5,33 & 5,72 & 5,47 & 5,60 & 0,012 & 0,108 \\
\hline $\mathrm{pH}(2)$ & 6,02 & 6,03 & 5,71 & 6,35 & 5,89 & 6,12 & 0,030 & 0,172 \\
\hline Turbidez (1) (UNT) & 14,76 & 14,30 & 11,90 & 18,60 & 13,85 & 15,00 & 3,430 & 1,852 \\
\hline Turbidez (2) (UNT) & 17,90 & 17,45 & 16,80 & 20,70 & 16,90 & 18,15 & 1,820 & 1,349 \\
\hline Condutividade (1) ( $\mu \mathrm{s} / \mathrm{cm})$ & 36,10 & 34,98 & 32,78 & 43,38 & 34,38 & 37,58 & 8,766 & 2,961 \\
\hline Condutividade (2) $(\mu \mathrm{s} / \mathrm{cm})$ & 20,29 & 20,15 & 18,00 & 24,70 & 18,95 & 20,95 & 3,080 & 1,755 \\
\hline STD (1) (mg/L) & 8,33 & 8,00 & 8,00 & 10,00 & 8,00 & 8,00 & 0,606 & 0,778 \\
\hline STD (2) (mg/L) & 9,50 & 9,50 & 9,00 & 10,00 & 9,00 & 10,00 & 0,273 & 0,522 \\
\hline Médio Moju & Md & Mda & Min & Max & $\mathrm{P} 25 \%$ & P75\% & Var & Dp \\
\hline Temperatura $(1)\left({ }^{\circ} \mathrm{C}\right)$ & 33,59 & 31,85 & 31,10 & 37,70 & 31,35 & 36,75 & 8,487 & 2,913 \\
\hline Temperatura $(2)\left({ }^{\circ} \mathrm{C}\right)$ & 28,31 & 28,05 & 27,90 & 28,90 & 27,95 & 28,85 & 0,215 & 0,464 \\
\hline $\mathrm{Ph}(1)$ & 5,13 & 5,13 & 5,00 & 5,26 & 5,40 & 5,22 & 0,011 & 0,104 \\
\hline $\mathrm{Ph}(2)$ & 5,76 & 5,78 & 5,26 & 6,36 & 5,47 & 5,97 & 0,133 & 0,364 \\
\hline Turbidez (1) (UNT) & 9,46 & 9,20 & 8,70 & 11,00 & 9,50 & 9,75 & 0,548 & 0,740 \\
\hline Turbidez (2) (UNT) & 25,44 & 27,80 & 18,88 & 29,80 & 2,83 & 28,80 & 19,824 & 4,452 \\
\hline Condutividade (1) ( $\mu \mathrm{s} / \mathrm{cm})$ & 13,92 & 13,90 & 13,80 & 14,10 & 13,80 & 14,15 & 0,013 & 0,116 \\
\hline Condutividade (2) ( $\mu \mathrm{s} / \mathrm{cm})$ & 18,10 & 17,95 & 17,70 & 18,60 & 17,80 & 18,50 & 0,140 & 0,374 \\
\hline STD (1) (mg/L) & 6,25 & 6,00 & 6,00 & 7,00 & 6,00 & 6,50 & 0,214 & 0,463 \\
\hline STD (2) (mg/L) & 8,375 & 8,00 & 8,00 & 9,00 & 8,00 & 9,00 & 0,268 & 0,517 \\
\hline Baixo Moјu & Md & Mda & Min & Max & $\mathrm{P} 25 \%$ & P75\% & Var & Dp \\
\hline Temperatura $(1)\left({ }^{\circ} \mathrm{C}\right)$ & 32,63 & 32,00 & 31,30 & 36,00 & 31,40 & 33,60 & 1,927 & 1,386 \\
\hline Temperatura $(2)\left({ }^{\circ} \mathrm{C}\right)$ & 30,50 & 30,50 & 30,20 & 31,00 & 30,30 & 30,70 & 0,514 & 0,227 \\
\hline $\mathrm{Ph}(1)$ & 5,23 & 5,22 & 5,20 & 5,48 & 5,10 & 5,37 & 0,199 & 0,141 \\
\hline $\mathrm{Ph}(2)$ & 5,62 & 5,64 & 5,00 & 5,93 & 5,55 & 5,74 & 0,538 & 0,232 \\
\hline Turbidez (1) (UNT) & 6,27 & 6,10 & 4,70 & 7,41 & 5,70 & 7,40 & 0,657 & 0,810 \\
\hline Turbidez (2) (UNT) & 15,42 & 15,30 & 12,70 & 19,20 & 13,80 & 16,80 & 3,496 & 1,870 \\
\hline Condutividade $(1)(\mu \mathrm{s} / \mathrm{cm})$ & 12,73 & 12,70 & 12,00 & 13,90 & 12,70 & 12,80 & 0,147 & 0,383 \\
\hline Condutividade (2) ( $\mu \mathrm{s} / \mathrm{cm})$ & 15,97 & 15,90 & 15,60 & 16,30 & 15,80 & 16,00 & 0,292 & 0,171 \\
\hline STD (1) (mg/L) & 6,00 & 6,00 & 6,00 & 6,00 & 6,00 & 6,00 & 0,00 & 0,00 \\
\hline STD (2) (mg/L) & 7,13 & 7,00 & 7,00 & 8,00 & 7,00 & 7,00 & 0,124 & 0,352 \\
\hline
\end{tabular}

Fonte: Elaborado pelos autores a partir dos dados processados. 
Gráfico 2. Variação da (a) Turbidez, (b) Condutividade Elétrica e (c) pH, médios nas sub-bacias do rio Moju durante o período chuvoso e menos chuvoso.
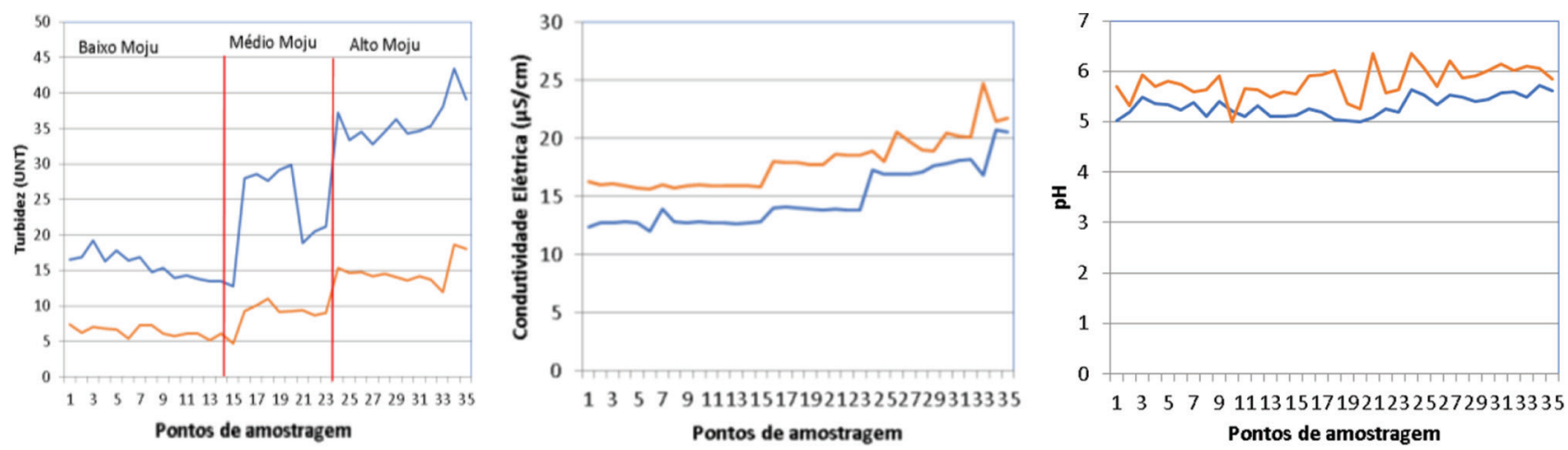

Fonte: Elaborado pelos autores a partir dos dados processados.

Gráfico 3. Classificação das águas das sub-bacias do rio Moju durante o período (a) menos chuvoso; (b) chuvoso.

(a)

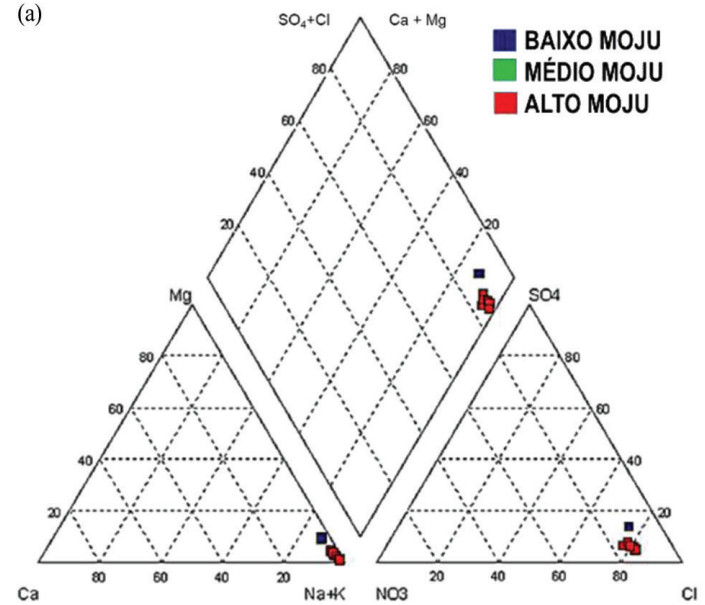

(b)

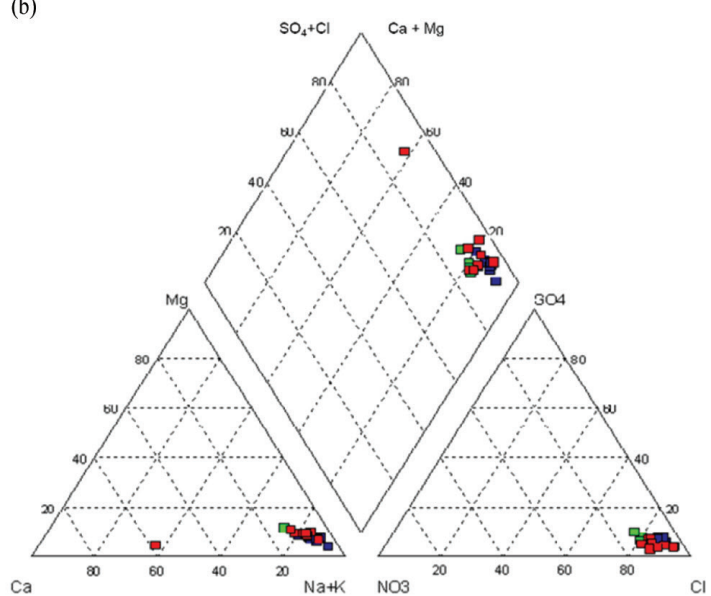

Fonte: Elaborado pelos autores a partir dos dados processados.

Admitindo a transição Médio-Alto Moju como a de maior frequência quantitativa do plantio do dendê $\hat{~}^{43}$, os resultados observados demonstram a importância do efeito da vazão do rio Moju, havendo apenas uma anomalia local de $\mathrm{Na}^{+}$no período menos chuvoso.

Quanto ao comportamento na transição Médio-Baixo Moju do $\mathrm{NO}_{3}^{-}$, tem-se a prevalência da estação menos chuvosa, porém neste segmento da bacia encontra-se a sede municipal de Moju e vários fragmentos florestais que se alternam entre o dendê e manchas de vegetação secundária, o que pode implicar em diversas fontes de contribuição para as águas superficiais. O Médio Moju concentrava em 2014 cerca de $34 \%$ de cobertura vegetal ("Floresta" e "Vegetação Secundária").

As Figuras 2 e 3 apresentam a síntese dos fatores que podem implicar como condicionantes de comportamento hidrogeomorfológico, bem como expor os cenários da paisagem observados. Estes concor-

\footnotetext{
43. Nahum e Santos, 2016
}

dam com o já discutido no zoneamento das áreas de maior pressão sobre os recursos naturais da bacia do rio Moju ${ }^{44}$.

Dentre os diversos aspectos associados às bacias hidrográficas amazônicas, que repercutem no observado para o rio Moju, merecem destaque os ligados ao planejamento de expansão das cidades, ao setor produtivo e ao monitoramento das águas, necessários para subsidiar o processo de tomada de decisão quanto à gestão de recursos hídricos ${ }^{45}$.

A bacia, ao ser tratada como um ambiente primário para a gestão da água, torna-se um espaço natural adequado para a discussão dos conflitos relacionados ao seu uso, no qual, a partir da abordagem hidropolítica, passa a ser admitido em função de suas diferentes escalas e áreas de interesse ${ }^{46}$.

As cidades componentes dos estados amazônicos tendem a ter uma forte conexão com as águas, bus-

\footnotetext{
44. Ferreira et al, 2017; Ferreira et al, 2020

45. Paiva et al, 2013; Ríos-Villamizar et al, 2014; Konzen et al, 2015

46. Olvera-Molina, 2016
} 
Gráfico 4. Comportamento da composição química das águas: (a) Baixo Moju; (b) Médio Moju; (c) Alto Moju. Período chuvoso (1) e menos chuvoso (2).
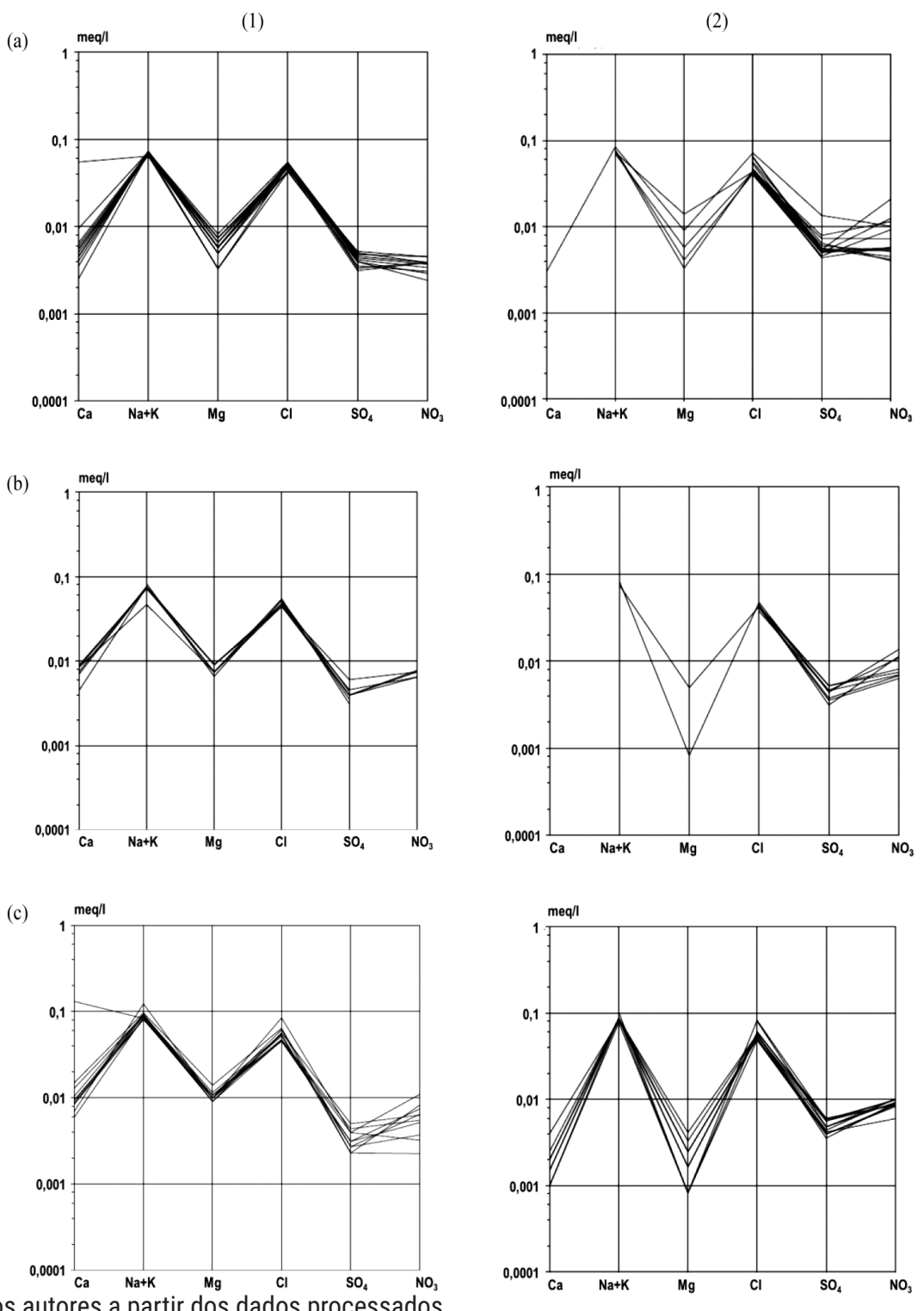

Fonte: Elaborado pelos autores a partir dos dados processados.

cando sua proximidade para moradia, navegação e aproveitamento econômico ${ }^{47}$. 0 contexto da bacia do rio Moju é concordante com este padrão, trazendo assim, diversos problemas associados à qualidade das águas.

Logo, destaca-se a necessidade do fortalecimento dos instrumentos vinculados à Política de Recursos Hídricos do Estado do Pará (Lei n. 6.381/2001), principalmente os relativos à "Outorga de Direito de Uso" e ao "Enquadramento dos Corpos de Água em Classes, Segundo os Usos Preponderantes da Água", como formas de regulação qualitativa e quantitativa e, principalmente, do "Plano da Bacia Hidrográfica do rio Moju", com foco nas ações de ordenamento territorial e inte-

\footnotetext{
47. Miranda et al, 2009; Gorayeb et al, 2010
}

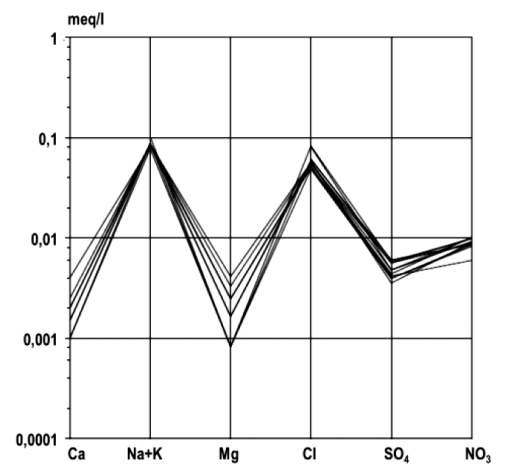

gração com as políticas públicas setoriais, vinculadas ao setor produtivo local e de saneamento básico das cidades.

\section{Conclusões}

A bacia do rio Moju, localizada no nordeste do estado do Pará, é uma importante unidade territorial de integração com o Centro-Sul do País, além de conter um dos polos econômicos regionais, vinculado ao plantio do dendê. $O$ contexto integrado das unidades de paisagem natural e antrópica, associado ao comportamento da qualidade das águas, permitiu inferir um conjunto de relações de causa e efeito, importantes de serem inves- 
Mapa 5. Uso e cobertura da terra e a variação da composição química das águas: Período menos chuvoso (1) e chuvoso (2).

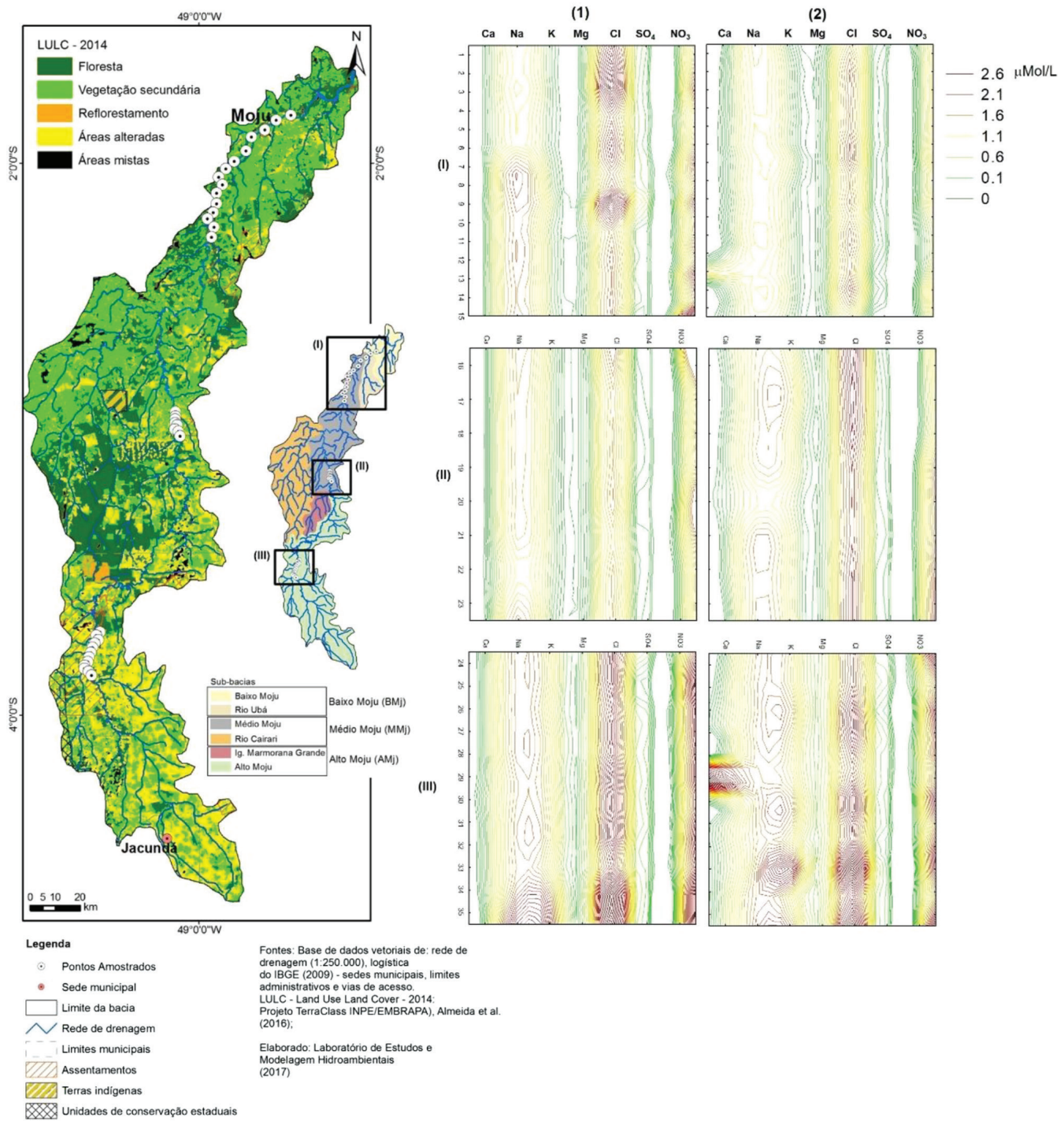

Fonte: Elaborado pelos autores a partir dos dados processados e da base cartográfica estruturada em SIG.

tigadas para a melhor compreensão dos fatores atuantes na região.

Os resultados indicam que as águas apresentam um comportamento entre cloretadas-sódicas e cálcicas com variações associadas principalmente aos efeitos da turbidez, às anomalias locais relativas, às formas de uso da terra e à presença do $\mathrm{NO}_{3}$.

As variações entre os períodos chuvoso e menos chuvoso são relevantes, assim como o efeito do comportamento da vazão, que somente é monitorada até o limite do Alto-Médio Moju, havendo necessidade de contabilizar a real contribuição do rio Cairari, que vai influenciar diretamente na qualidade das águas que drenam a área de maior ocorrência de alterações de uso da terra, por diversas atividades, especialmente o dendê.

A análise integrada dos resultados também ressalta que as formas de uso da terra de 2010 a 2017, observa- das pelos mapeamentos avaliados, apresentaram em comum a persistência de alteração do Alto Moju, principal responsável pela recarga hídrica da bacia, o que aponta para a proposição de políticas ambientais, de expansão do setor produtivo (agropecuário e extrativista) e de desenvolvimento de espaços urbanos mais correlacionadas, de forma a fomentar áreas de recomposição da cobertura vegetal em regiões mais estratégicas para oferta de água.

No relativo à gestão de recursos hídricos da bacia, recomenda-se o monitoramento continuado quali-quantitativo das águas e o planejamento integrado com outras políticas setoriais. Ações como o enquadramento e a classificação dos corpos de água, segundo classes de uso, e a maior ampliação das formas de regularização, como a outorga de direito das águas, deveriam ser melhor sistematizadas para a bacia, pois 
Figura 2. Fatores de influência direta na qualidade das águas, segundo as variáveis (Var.) avaliadas.

\begin{tabular}{ll}
\hline Var. & Alto Moju \\
\hline Hidrogeomorfologia & Formado principalmente pelos sedi- \\
& mentos do Grupo Itapecuru; marcado \\
& por formas de dissecação, com maior \\
& variação altimétrica e controle estru- \\
& tural; os indicadores morfométricos \\
& descrevem como comportamento \\
& potencial de escoamento.
\end{tabular}

Médio Moju Baixo Moju

Formado principalmente pelos sedimentos da Formação Ipixuna; com formas de dissecação, que gradam para mais Formado principalmente pelos sedimentos do Grupo Barreiras; com formas de disseplanas. A sub-bacia do rio Cairari é a prin- Os indicadores morfométricos isolam esta cipal sub-bacia da região. Os parâmetros região, que possui uma ampla planície morfométricos aproximam o Alto e 0 de inundação e intensa acumulação de Médio Moju, favorecendo o escoamento, sedimentos, com a maior largura do vale porém a ocorrência de áreas mais planas do canal principal. possibilita a presença de zonas de maior acumulação de sedimentos.

\begin{tabular}{lll}
\hline Quantitativo das águas & $\begin{array}{l}\text { É a região melhor representada pelos } \\
\text { dados de chuva/vazão com máximos }\end{array}$ & É região que apresenta uma variação \\
& (período chuvoso) de $368 \mathrm{~mm}$ e 353 & maior que $90 \%$. Recebe na de chuvas porção \\
$\mathrm{m}^{3} / \mathrm{s}$ e mínimos (período menos & mediana a sub-bacia do rio Cairari, o que \\
chuvoso) de $17 \mathrm{~mm}$ e $48 \mathrm{~m}^{3} / \mathrm{s}$ (média & indicaria um incremento do efeito de \\
mensal do período). Uma variação & diluição e do potencial de transporte de \\
maior que $80 \%$ em ambos os casos. & sedimentos.
\end{tabular}

Apresenta uma variação entre o máximo e o mínimo de chuvas maior que $80 \%$. E recebe o maior volume de chuvas durante todo o período. Trata-se de uma área com regime de maré, onde a vazão tem regime variável e impacta no comportamento da qualidade das águas e transporte de sedimentos.

$\begin{array}{ll}\text { Qualitativo das águas } & \text { Maiores valores de turbidez e } \\ & \text { condutividade éétrica em ambos os } \\ & \text { períodos avaliados, concentrando o } \\ & \text { padrão de águas cloretadas-sódicas } \\ \text { no menos chuvoso e uma gradual } & \text { tendência para um comportamento } \\ \text { de águas mais cálcicas no chuvoso }\end{array}$

Valores de turbidez, condutividade elétri- Valores de turbidez e condutividade ca e pH variáveis em ambos os períodos elétrica foram os menores detectados. avaliados. Manteve-se o padrão de águas Manteve-se o padrão de águas clorecloretadas-sódicas no menos chuvoso tadas-sódicas durante todo o período. e uma gradual tendência para um com- Observa-se o efeito de diluição do período portamento de águas mais cálcicas no chuvoso, com a redução da concentração chuvoso, sendo mais intenso neste que dos cátions e íons avaliados. no Alto Moju.

Uso e cobertura da terra

Encontra-se influenciado pelas sedes municipais de Jacundá, Breu Branco e Goianésia do Pará. É segmentado também por um conjunto de vias de acesso que fazem a conexão com a sede municipal de Tucuruí (e com a UHE de Tucuruí). A presença de áreas urbanas, vilas e povoados gera como elemento de alteração da qualidade das águas o esgotamento sanitário, lançado in natura nos corpos hídricos, pois a região não apresenta sistemas de coleta e tratamento de esgoto.

\begin{tabular}{|c|c|}
\hline $\begin{array}{l}\text { Encontra-se em uma região alterada com } \\
\text { fragmentos de vegetação que incluem } \\
\text { as áreas destinadas ao plantio de dendê, } \\
\text { além da produção agropecuária. } 0 \\
\text { mosaico de ocupações é influenciado } \\
\text { pela presença na borda da bacia da } \\
\text { sede municipal de Tailândia, de vicinais } \\
\text { e rodovias que integram o eixo norte-sul } \\
\text { e leste-oeste da bacia. A maior área de } \\
\text { cobertura florestal é encontrada nas } \\
\text { cabeceiras do rio Cairari, porém ao longo } \\
\text { do rio Moju a segmentação é elevada. }\end{array}$ & $\begin{array}{l}\text { Apresenta a melhor cobertura de área } \\
\text { florestal ao longo do rio Moju, porém a } \\
\text { maior parte da vegetação é secundária, } \\
\text { alternada com áreas alteradas e mosaicos } \\
\text { de ocupações. Presença da sede munici- } \\
\text { pal de Moju que é um importante conector } \\
\text { da região, via Alça Viária, com a Região } \\
\text { Metropolitana de Belém (RMB), fazendo } \\
\text { com que esta área seja diretamente } \\
\text { impactada por uma dinâmica de trânsito } \\
\text { de pessoas, bens e serviços em direção } \\
\text { a RMB. }\end{array}$ \\
\hline
\end{tabular}

Fonte: Elaborado pelos autores.

Figura 3. Cenários avaliados para a bacia do rio Moju.

\begin{tabular}{|c|c|c|c|}
\hline Var. & Alto Moju & Médio Moju & Baixo Moju \\
\hline Cenários & $\begin{array}{l}\text { Corresponde à região de maior } \\
\text { potencial de alteração da qualidade } \\
\text { das águas pelas formas de uso da } \\
\text { terra. } \\
\text { O volume de chuvas contribui de } \\
\text { forma significativa para a vulner- } \\
\text { abilidade natural de produção de } \\
\text { sedimentos (pela relação entre os } \\
\text { litotipos presentes com o grau de } \\
\text { dissecação do terreno), associada } \\
\text { à intensa remoção da cobertura } \\
\text { vegetal, à abertura de estradas, } \\
\text { à urbanização e expansão de } \\
\text { áreas destinadas ao mosaico de } \\
\text { ocupações e ao aproveitamento } \\
\text { agropecuário. }\end{array}$ & $\begin{array}{l}\text { Região potencial de alteração da quali- } \\
\text { dade das águas. Neste trecho de bacia a } \\
\text { qualidade das águas é influenciada pela het- } \\
\text { erogeneidade da paisagem, com a presença } \\
\text { de áreas mistas com cobertura florestal e } \\
\text { alterada, além de receber um incremento de } \\
\text { vazões pela ação das águas do rio Cairari. } \\
\text { Esta variação é bem notada entre os } \\
\text { períodos chuvoso e menos chuvoso, uma } \\
\text { vez que a redução do volume de chuvas é de } \\
\text { cerca de } 90 \% \text {. Por se tratar de uma região } \\
\text { de forte vocação agrícola, pode-se destacar } \\
\text { como efeito potencial de alteração da } \\
\text { qualidade das águas o uso de fertilizantes. } \\
\text { Constatou-se que os valores que os valores } \\
\text { de NO } 0_{3}^{3} \text { mantiveram-se no mesmo padrão do } \\
\text { Alto Moju, sendo que neste havia uma forte } \\
\text { contribuição do mosaico de ocupações e de } \\
\text { áreas urbanas. }\end{array}$ & $\begin{array}{l}\text { Região potencial de alteração da qualidade das } \\
\text { águas. A sede municipal de Moju está localizada } \\
\text { nas margens do rio Moju e tem uma interação } \\
\text { direta com este, com o lançamento de efluentes e } \\
\text { interface do setor portuário e de transporte (arma- } \\
\text { zenamento) de cargas nas margens deste. } \\
\text { A redução do impacto gerado pelas alterações é } \\
\text { minimizado pelo volume de águas, admitindo a } \\
\text { mesma relação de vazão de referência estimada } \\
\text { para o rio Cairari, o rio Moju chegaria na foz com } \\
\text { uma descarga superior a } 900 \mathrm{~m}^{3} / \mathrm{s} \text { no período } \\
\text { chuvoso e superior a } 100 \mathrm{~m}^{3} / \mathrm{s} \text { no período menos } \\
\text { chuvoso, este tipo de estimativa não considera } \\
\text { perdas, admite a conversão da vazão apenas em } \\
\text { função da área da bacia, porém permite exempli- } \\
\text { ficar que a redução dos efeitos de alteração da } \\
\text { qualidade das águas não pode ser desprezada, } \\
\text { apenas ponderada pelo potencial de diluição das } \\
\text { águas. }\end{array}$ \\
\hline
\end{tabular}

Fonte: Elaborado pelos autores. 
reproduziriam um cenário de ordenamento necessário para a manutenção da sua disponibilidade e atendimento da demanda em qualidade e quantidade de suprimento de água.

\section{Agradecimentos}

À Fundação Amazônia de Amparo a Estudos e Pesquisas do Estado do Pará (FAPESPA), ao Conselho Nacional de Desenvolvimento Científico e Tecnológico (CNPq) e à Coordenação de Aperfeiçoamento de Pessoal de Nível Superior (CAPES) pelo apoio ao desenvolvimento da pesquisa.

\section{REFERÊNCIAS}

Almeida, C. A., Coutinho, A. C., Esquerdo, J. C. D. M., Adami, M., Venturieri, A., Diniz, C. G., Dessay, N., Durieux, L. y Gomes, A. R. 2016: "High spatial resolution land use and land cover mapping of the Brazilian Legal Amazon in 2008 using Landsat-5/TM and MODIS data". Acta Amazônica, 46, 3, 291-302. https://doi.org/10.1590/1809-4392201505504

Alves, J. M. P. y Castro, P. T. A. 2003: "Influência de feições geológicas na morfologia da bacia do rio Tanque (MG) baseada no estudo de parâmetros morfométricos e análise de padrões de lineamentos". Revista Brasileira de Geociências, 33, 2, 117127. https://doi.org/10.25249/0375-7536.2003332117124

APHA. 1995: American Public Health Association. Standard Methods for the Examination for Water and Wastewater. Washington, Byrd Prepess Springfield.

Aprile, F. M. y Darwich, A. J. 2009: "Regime térmico e a dinâmica do oxigênio em um lago meromítico de águas pretas da região Amazônica". Brazilian Journal of Aquatic Science and Technology, 13, 37-43. http://dx.doi.org/10.14210/bjast.v13n1

Bentes, E. S. y Homma, A. K. 0. 2016: Importação e exportação de óleo e palmiste de dendezeiro no Brasil (2010-2015). Belém, Embrapa Amazônia Oriental.

Chapman, D. V., Bradley, C., Gettel, G. M., Hatvani, I. G., Hein, T., Kovács, J., Liska, I., Oliver, D. M., Tanos, P., Trásy, B. y Várbíró, G. 2016: "Developments in water quality monitoring and management in large river catchments using the Danube River as an example". Environmental Science \& Policy, 64, 141154. https://doi.org/10.1016/j.envsci.2016.06.015

Christofoletti, A. 1980:Geomorfologia. SãoPaulo, EdgardBlücher. Conley, D. J., Paerl, H. W., Howarth, R. W., Boesch, D. F., Seitzinger, S. P., Havens, K. E., Lancelot, C. y Likens, G. E. 2009: "Controlling eutrophication: nitrogen and phosphorus". Science, 323, 1014-1015. https://doi.org/10.1126/science.1167755
Corrêa-Martins, F. J., Mendes, J. C., Bertolino, L. C. y Mendonça, J. 0. 2018: "Petrografia, Diagênese e Considerações sobre Proveniência da Formação Itapecuru no Norte do Maranhão (Cretáceo Inferior, Bacia do Parnaíba, NE Brasil)". Anuário do Instituto de Geociências, 41-3, 514-530.

Coutinho, A. C, Almeida, C, Venturieri, A., Esquerdo, J. C. D. M. y Silva, M. 2013: Uso e cobertura da terra nas áreas desflorestadas da Amazônia Legal: TerraClass 2008. Brasília, EMBRAPA, INPE.

Cristancho, J. A. R., Hanafi, M. M., Omar, S. R. y Rafii, M. Y. 2011: "Alleviation of aluminum in acidic soils and its effect on growth of hybrid and clonal oil palm seedlings". Journal of Plant Nutrition, 34, 3, 387-401. https://doi.org/10.1080/01904 167.2011 .536880

Davidson, E. A., Neill, C., Krusch, A. V., Ballester, V. V. R., Markewitz, D. y Figueiredo, R. D. 0. 2004: "Loss of nutrients from terrestrial ecosystems to streams and the atmosphere following land use change in Amazonia", in: Asner, G. y Fries, R. (Eds.): Ecosystems and Land Use Change. Washington D. C., American Geophysical Union, 147-158. https://doi.org/10.1029/153GM12

Desta, H. y Lemma B. 2017: "SWAT based hydrological assessment and characterization of Lake Ziway sub-watersheds, Ethiopia". Journal of Hydrology, 13, 122-137. https://doi. org/10.1016/j.ejrh.2017.08.002

Donadio, N. M. M., Galbiatti, J. A. y Paula, R. C. 2005: "Qualidade da água de nascentes com diferentes usos do solo na bacia hidrográfica do Córrego Rico, São Paulo, Brasil". Engenharia Agrícola, 25, 1, 115-125. https://doi.org/10.1590/S010069162005000100013

Ferreira, S. C. G., Lima, A. M. M. y Correa, J. A. M. 2017: "Zoneamento da bacia hidrográfica do rio Moju (Pará): usos da água e sua relação com as formas de uso e cobertura do solo". Revista Ambiente \& Água, 12, 4, 680-693. http://doi. org/10.4136/ambi-agua.2069.

Ferreira, S. C. G., Lima, A. M. M. y Correa, J. A. M. 2020: "Indicators of hydrological sustainability, governance and water resource regulation in the Moju river basin (PA) - Eastern Amazonia". Journal of Environmental Management, 263, 110354, 1-10. https://doi.org/10.1016/j.jenvman.2020.110354

Ferreira, S. C. G., Silva, L. M., Lima, A. M. M. y Correa, J. A. M. 2016: "A sustentabilidade hídrica da bacia hidrográfica do rio Moju a partir de indicadores de disponibilidade e demanda", in: Silva, C. N., Bordalo, C. A. L. y Silva, E. V. (coords.): Planejamento, conflitos e desenvolvimento sustentável em bacias hidrográficas: experiências e ações. Belém, GAPTA/UFPA, 601-630. 
Figueiredo, R. 0. 2009: "Processos hidrológicos e biogeoquímicos em bacias hidrográficas sob uso agrícola e agroflorestal na Amazônia brasileira", in: Porro, R. (Ed.): Alternativa agroflorestal na Amazônia em transformação, Brasilia, EMBRAPA, 478-500.

Franzini, V. I., Baizi e Silva, A. R. y Gomes Junior, R. A. 2012 Acidez do solo e sua correção em palma de óleo. Belém, EMBRAPA.

Gerber, D., Pertille, C. T., Vieira, F. S., Corrêa, B. J. S. y Souza, C. F. 2018: "Caracterização morfométrica da Bacia Hidrográfica do Rio Itajaí - Santa Catarina”. Acta Biológica Catarinense, 5, 1, 72-83. https://doi.org/10.21726/abc.v5i1.446

Gorayeb, A., Lombardo, M. A. y Carneiro Pereira, L. C. 2010 : "Qualidade da água e abastecimento na Amazônia: o exemplo da bacia hidrográfica do rio Caeté". Mercator, 9, 18, 135-157. https://doi.org/10.4215/RM2010.0918.0011

Hanna, N., Lartiges, B., Kazpard, V., Maatouk, E., Amacha. N., Sassine, S. y El Samrani, A. 2018: "Hydrogeochemical processes in a small eastern mediterranean karst watershed (Nahr Ibrahim, Lebanon)". Aquatic Geochemistry, 24, 5-6, 325344. https://doi.org/10.1007/s10498-018-9346-x

Horbe, A. M. C., Queiroz, M. M. A., Moura, C. A. V. y Toro, M. A. G. 2013: "Geoquímica das águas do médio e baixo rio Madeira e seus principais tributários - Amazonas - Brasil". Acta Amazônica, 43, 4, 489-504. https://doi.org/10.1590/S004459672013000400011

IBGE. 2009: Manual técnico de geomorfologia. Rio de Janeiro-RJ, Instituto Brasileiro de Geografia e Estatística-IBGE, $182 \mathrm{p}$.

Kato, 0. R., Kato, M. S., Sá, T. D. A. y Figueiredo, R. 0. 2004 "Plantio direto na capoeira". Ciência e Ambiente, 29, 99-111.

Konzen, G. B., Figueiredo, J. A. S. y Quevedo, D. M. 2015: "History of water quality parameters - a study on the Sinos River/Brazil". Brazilian Journal of Biology, 75, 2 (suppl.), 1-10. http://doi.org/10.1590/1519-6984.0213

Macambira, E. M. B. y Ricci, P. S. F. 2013: Geologia e recursos minerais da Folha Tucuruí: SA.22-Z-C, Estado do Pará, Escala 1:250.00. Belém, CPRM - Serviço Geológico do Brasil.

Marques, R., Zamparoni, C. A. G. P., Castro E Silva, E., Magalhães, A., Guedes, S. F. y Fornaro, A. 2010: "Composição química de águas de chuva em áreas tropicais continentais, Cuiabá-MT: aplicação do Sistema Clima Urbano (S.C.U.)". Revista do Departamento de Geografia, 20, 63-75. http://doi. org/10.7154/RDG.2010.0020.0005

Masanobu Shimada, T. I., Takeshi Motooka, M. W., Shiraishi Tomohiro, R. T. y Richard, L. 2014: "New Global Forest/Non-forest Maps from ALOS PALSAR Data (2007-2010)". Remote Sensing of Environment, 155, 13-31. http://doi.org/10.1016/j. rse.2014.04.014
Mioto, C. L., Oliveira, R. V., Queiroz, S. D. M., Pereira, T. V., Anache, J. A. A. y Paranhos, F. A. C. 2017: "Morfometria de bacias hidrográfcas através de SIGs livres e gratuitos". Anuário do Instituto de Geociências, 37, 2, 16-22. https://doi. org/10.11137/2014_2_16_22.

Miranda, R. G., Pereira, S. F. P., Alves, D. T. V. y Oliveira, G. R. F. 2009: "Quality of water resources in the Amazon region - Rio Tapajós: Assessing the case for chemical elements and physical-chemical parameters". Revista Ambiente \& Água, 4, 2, 75-92. https://doi.org/10.4136/ambi-agua.88.

Moura, L. H. A., Boaventura, G. R. y Pinelli, M. P. 2010: "A qualidade de água como indicador de uso e ocupação do solo: bacia do Gama - Distrito Federal". Química Nova, 33, 1, 97-103. http://doi.org/10.1590/S0100-40422010000100018

Nahum, J. S. y Santos, C. B. 2013: "Impactos socioambientais da dendeicultura em comunidades tradicionais na Amazônia paraense". ACTA Geográfica, 63-80. http://dx.doi.org/10.5654/ acta.v0i0.1953

Nahum, J. S. y Santos, C. B. 2016: "A dendeicultura na Amazônia paraense". GeoUSP, 20, 2, 281-294. http://doi.org/10.11606/ issn.2179-0892.geousp.2016.122591

Niraula, R., Meixner, T. y Norman, L. M. 2015: "Determining the importance of model calibration for forecasting absolute/ relative changes in streamflow from LULC and climate changes". Journal of Hydrology, 522, 439-451. http://doi. org/10.1016/j.jhydrol.2015.01.007

Oki, T. y Kanae, S. 2006: "Global hydrological cycles and world water resources". Science, 313, 1068-1072. http://doi. org/10.1126/science. 1128845

Olvera-Molina, M. 2016:" Desnaturalizando la cuenca en México: notas sobre el espacio hidropolítico". Agua y Territorio, 7, 11-21. http://doi.org/10.17561/at.v0i7.2959

Paiva, R., Buarque, D., Collischonn, W., Bonnet M-P, Frappart, F., Calmant, S. y Mendes, C. 2013: "Large-scale hydrologic and hydrodynamic modelling of the Amazon River basin". Water Resources Research, 49 (3), 1226-1243. http:// doi.org/10.1002/wrcr.20067

Pareta, K. y Pareta, U. 2012: "Quantitative Geomorphological Analysis of a Watershed of Ravi River Basin, H. P. India". International Journal of Remote Sensing and GIS, 1, 1, 41-56.

Ríos-Villamizar, E. A., Martins, A. F. y Waichman, A. V. 2011: "Caracterização físico-química das águas e desmatamento na Bacia do rio Purus, Amazônia Brasileira Ocidental". Geográfica Acadêmica, 5, 2, 54-65.

Ríos-Villamizar, E. A., Piedade, M. T. F., Costa, J. G., Adeney, J. M. y Junk, W. J. 2014: "Chemistry of different Amazonian water types for river classification: a preliminary review". Transactions on Ecology and The Environment, 178, 17-28. http:// dx.doi.org/10.2495/13WS 0021 
Rocha, P. C. y Santos, A. A. 2018: "Análise Hidrológica em Bacias Hidrográficas". Mercator, 17, 1-18. http://doi.org/10.4215/ rm2018.e17025

Ross, J. L. S. 1992: "O registro cartográfico dos fatos geomorfológicos e a questão da taxonomia do relevo". Revista do Departamento de Geografia, 6, 17-29. http://doi.org/10.7154/ RDG.1992.0006.0002

Rossetti, D. F. 2006: "Evolução sedimentar miocênica nos Estados do Pará e Maranhão". Geologia USP, 6, 2, 7-18. https://doi. org/10.5327/S1519-874X2006000300003

Sala, O. E., Chapin, I. F. S., Armesto, J. J., Berlow, E., Bloomfield, J., Dirzo, R., Huber Sanwald, E., Huenneke, L. F., Jackson, R. B., Kinzig, A., Leemans, R., Lodge, D. H., Mooney, H. A., Oesterheld, M., Leroy Poff, N., Sykes, M. T., Walker, B. H., Walker, M. y Wall, D. H. 2000: "Global biodiversity scenarios for the year 2100". Science, 287 (5459), 1770-1774. http://dx.doi. org/10.1126/science.287.5459.1770

Sanson, L. M. y Hernández, F. G. 2018: "Apropiación territorial y recursos hídricos en la cuenca de los ríos Grijalva y Usumacinta, México". Agua y Territorio, 12, 133-144. http://doi. org/10.17561/at.12.3505

Santos Junior, A. E. y Rossetti, D. F. 2003: "Paleoambiente e estratigrafia da Formação Ipixuna, área do Rio Capim, leste da Sub-bacia de Cametá". Revista Brasileira de Geociências, 33, 313-324.

Santos, J. C., Homma, A. K. O., Sena, A. L. S., Gomes Júnior, R. A., Menezes, A. J. E. A. Y Monteiro, K. F. G. 2014: Desempenho socioeconômico do sistema produtivo familiar de dendê em Moju, Estado do Pará. Belém, Embrapa Amazônia Oriental.

Silva, E. M. y Navegantes-Alves, L. 2017: "L'occupation de l'espace par le palmier à l'huile et ses effets sur la production agricole familiale en Amazonie orientale". CONFINS, 30. http:// doi.org/10.4000/confins. 11843
Silva, M. S. R., Miranda, S. A. F. y Santana, G. P. 2016: "Bacia Hidrográfica do Rio Amazonas: Condições de suas águas versos Resolução N 357/CONAMA/2005". Scientia Amazônia, 6, 2, 83-90.

Soares Junior., A. V., Costa, J. B. S. y Hasui, Y. 2008: "Evolução da margem atlântica equatorial do Brasil: três fases distensivas". Geociências, 27, 4, 427-437.

Toledo, L. G. y Nicolella, G. 2002: "Índice de qualidade de água em microbacias sob uso agrícola e urbano". Scientia Agricola, 59, 1, 181-186. http://doi.org/10.1590/S0103-901620020001 00026

Umbuzeir O. G. A., Kummrow, F. y Rei, F. F.C. 2010: "Toxicologia, padrões de qualidade de água e a legislação". INTERFACEHS, 5, 1, 1-15.

Varol, M., Gökot, B., Bekleyen, A. y Şen, B. 2012: "Spatial and temporal variations in surface water quality of the dam reservoirs in the Tigris River basin, Turkey". Catena, 92, 11-21. http://doi.org/10.1016/j.catena.2011.11.013

Vasquez, M. L. y Rosa-Costa, L. T. 2008: Geologia e Recursos Minerais do Estado do Pará: Sistema de Informações Geográfcas - SIG, texto explicativo dos mapas Geológico e Tectônico e de Recursos Minerais do Estado do Pará. Belém, CPRM - Serviço Geológico do Brasil, 328 p.

Wang, Y., Liu, C., Liao, P. y Lee, J. 2014: "Spatial pattern assessment of river water quality: implications of reducing the number of monitoring stations and chemical parameters". Environmental Monitoring and Assessment, 186, 3, 1781-1792. http://doi.org/10.1007/s10661-013-3492-9

Watrin, O. S, Gerhard, P. y Maciel. M. N. M. 2009: "Dinâmica do uso da terra e configuração da paisagem em antigas áreas de colonização de base econômica familiar, no nordeste do estado do Pará". Geografia, 34, 3, 455-472. 